\title{
Global Motion and Airgap Computations for Semi-submersible Floating Production Unit in Waves
}

\author{
Xinshu Zhanga,b,*, Xingyu Song ${ }^{a, b}$, Zhiming Yuanc, Yunxiang You ${ }^{\mathrm{a}, \mathrm{b}}$ \\ ${ }^{a}$ State Key Laboratory of Ocean Engineering, Shanghai Jiao Tong University, \\ Shanghai, 200240, China \\ ${ }^{b}$ Collaborative Innovation Center for Advanced Ship and Deep-Sea Exploration (CISSE), \\ Shanghai, 200240, China \\ ${ }^{c}$ Department of Naval Architecture, Ocean and Marine Engineering, University of Strathclyde, \\ Glasgow, G4 OLZ, UK
}

\begin{abstract}
We study the global hydrodynamic performance of a semi-submersible floating platform unit in order to optimize the hull form in the future. The hydrodynamic problem is solved by employing potential flow theory and Morison equation for modelling of the viscous effects. The added mass and damping coefficients, as well as the first-order motion responses, second-order mean drift forces, diffracted and radiated wave field, and airgap are computed to examine the hydrodynamic behavior of the floating production unit. The computational results show that the motion responses in short-crested waves are mostly smaller than those in long-crested waves. The maximum wave elevation occurs at WP45 in $45^{\circ}$ wave heading in long-crested waves. In addition, the minimum airgap occurs at AG45 in $45^{\circ}$ wave heading in linear waves, while the worst airgap point in nonlinear waves is AG0 in $0^{\circ}$ wave heading.

Extensive parametric studies have been performed to examine the dependence of the motion responses and the other key design criteria on the principal dimensions including hull draft, column width, column spacing, column corner radius, pontoon height, pontoon width, and the size of cakepiece. By comprehensive and systematic hydrodynamic computations and analyses, it is revealed that the combined vertical motion at the worst airgap location is almost in phase with the wave elevation in extreme wave condition with a peak wave period around 14 to 15 seconds. Moreover, it is found that the most efficient way to reduce the motion is to increase the hull draft, though the airgap may also decrease. Besides, reducing the pontoon height can achieve better motion performance and larger airgap simultaneously. This paper aims to provide a benchmark for future studies on automatic hull form optimization.
\end{abstract}

\section{Introduction}

Tension Leg Platform (TLP), Spar, and Semi-submersible (SEMI) are the three major floater concepts adopted for oil/gas exploration and offshore wind energy extraction in the past few decades. SEMI shows more advantages over the other two in deep water applications. For instance, as the operation water depth goes beyond 1200 meters, the cost of implementing a TLP concept increases rapidly. Spar is neither a cost-effective solution as most of the commissioning work and the hull \& topside integration have to be performed offshore, despite of its

*Corresponding author; Director, Innovative Marine Hydrodynamics Laboratory (iMHL).

Email address: xinshuz@sjtu.edu.cn (Xinshu Zhang) 
impressive vertical motion performance (Mansour and Kumar, 2013). In addition, limited deck area and payload can be supported by a Spar platform because of its single column configuration. On the other hand, SEMI is a cost-efficient solution for intermediate and deep water depth with relatively larger payload. Furthermore, SEMI has no restriction on fabrication location as it can be built by a number of shipyards worldwide. Therefore, semi-submersible floating production unit (FPU) is becoming increasingly popular with concept selection for the application in either intermediate or deep water depth. However, in deep water oil and gas exploration, one of the major challenges for designing a semi-submersible is the relatively larger vertical motion in waves, which makes it difficult to design robust and reliable mooring and riser systems. For example, popularly adopted for deep water oil and gas exploration, Steel Catenary Riser (SCR) can be significantly impacted by the vertical motion of a semi-submersible FPU due to strength and fatigue issues near the touchdown point on seabed (Xia et al., 2008). Therefore, optimization of the hull form to reach better global motion performance is critical to the development of a SEMI FPU or a drilling platform. In addition, the recent research and development on dry-tree SEMI also requires a concept with better heave motion performance (Lu et al., 2013).

In order to minimize the hydrodynamic force, many researches have been conducted to investigate the effects of "Dog-bone" concept (Nishimoto and Leite, 1993; Clauss and Birk, 1994; Lee and Clauss, 2007b). It was confirmed that the "Dog-bone" configuration can reduce the wave-induced loads on the ring pontoons. Later, Xu (2011) proposed a so-called HVS SEMI concept to minimize the heave motion of a platform by placing blisters at the corners between the column and pontoon. Through model test in towing tank, it was confirmed that the blister can break the vortex shedding coherence in vertical direction so that the Vortex Induced Motion (VIM) of a deep-draft SEMI in current can be somehow suppressed (Xu et al., 2012). Meanwhile, a couple of other SEMI concepts have been proposed through applying heave plates to minimize the wave induced heave response (Cermelli et al., 2004; Roddier et al., 2010; Liapis et al., 2015).

Regarding the automatic optimization algorithm, Akagi and Ito (1984) proposed a method to optimize a drilling SEMI based on analytical formulations of the computations of wave forces and heave response. Lee and Clauss (2007a) optimized a semi-submersible design by using the downtime as an objective function. Later, the optimizing approach has been extended to multi-objective optimization (Akagi et al., 1984; Birk, 2007) for semi-submersibles. This type of approach has also been applied to the other types of floaters, such as TLP and Spar (Birk and Clauss, 2008; Lee et al., 2007; Lee and Lim, 2008). In addition, Venzon et al. (2013) proposed an artificial neural network model for hull form optimization of a semi-submersible drilling rig. This method does not require extensive numerical computations of the hydrodynamic loads so that the computational cost can be significantly reduced. More recently, Park et al. (2015) optimized a SEMI FPU by using a simulated annealing (SA) algorithm with constraining the metacentric height (GM). However, most of the previous studies focused on the aspect of optimization scheme. There is little literature on comprehensive hydrodynamic computations for quantification of the effects of hull main dimensions on the first and second-order motions, wave elevation, and airgap.

In fact, not only heave motion, but also surge and sway motions can impact the fatigue life of a SCR near the touchdown point, in particular for the applications at intermediate water depth around 2000 meters. In addition, the airgap, defined as the minimum distance between the wave surface and the deck bottom, is also 
one of the critical criteria for performance evaluation of a FPU in either Gulf of Mexico (GOM) or North Sea (API RP 2SK, 2005). The negative airgap means that wave impact/slamming can occur and the hull/topside may be damaged. Furthermore, the second-order mean drift forces should also be taken into account in the course of optimization because they can significantly affect the mooring and riser systems.

The principal focus of this paper is to investigate the dependence of a semi-submersible FPU's the global motion performance on its main particulars, which lays the ground work for hull form's optimization study in the future. The rest of the paper is organized as follows. First, we give the mathematical formulation including the computational approaches for the evaluation of hydrodynamic loads, motion responses, mean drift forces, wave elevations and airgap. Second, the hydrodynamic behavior of SEMI FPU are systematically examined by employing a classic boundary element method code WADAM. Third, extensive parametric studies have been performed to examine the physical effects of principal dimensions on the motion performance, second-order mean drift forces, diffracted wave field, and airgap. Finally, conclusions are given based on the aforementioned simulations.

\section{Mathematical Formulation and Numerical Models}

We study the three-dimensional wave-structure interaction problem in deep water. The floating unit is positioned by a taut or semi-taut mooring system. The total external forces acting on the structure can be decomposed into wave-induced force and viscous drag force. The wave force acting on large-scale structural components, such as columns and pontoons of a semi-submersible, can be computed based on potential flow theory. The viscous drag force can be evaluated by Morison equation.

\subsection{Wave-structure interaction}

The sketch of the problem for a typical SEMI FPU is shown in Figure 1. The submerged hull structure consists of a ring pontoon and four columns, which are located in Northwest (NW), Northeast (NE), Southwest (SW), and Southeast (SE), respectively. The mean submerged hull surface is modelled. The main particulars of the hull are illustrated in Figure 1. The draft of the hull is denoted as Draft. The spacing between the centers of two adjacent columns is $C S$. The width of the column is $C W$. The width and height of the pontoon are defined as $P W$ and $P H$, respectively. The column corner radius is denoted as $C C R$. The width of cakepiece is denoted as $C P$. The fluid is assumed to be ideal and the flow irrotational. The fluid density is defined as $\rho$. Since the floating structure is symmetric about $x$ and $y$ axes, only the fluid domain with $x \geq 0$ and $y \geq 0$ is considered. The definition of the incident wave heading is illustrated in Figure 2, where a plan view of the FPU is presented.

A boundary value problem (BVP) for a floating structure in deep water is solved. The floating unit may undergo unsteady oscillations in its six degrees of freedom. Two coordinate systems are employed: the $x_{o}$ system is fixed to the mean position of the floating body, and the x system is fixed to the moving hull. The boundary value problem is solved in the right-hand fixed coordinate system, as shown in Figure 1. The x-axis points to the direction of platform east (PE) and the z-axis points upward. The origin is on the calm water plane at mid-section of the hull. In the $x_{o}$ coordinate system, a velocity potential is introduced to describe the fluid 


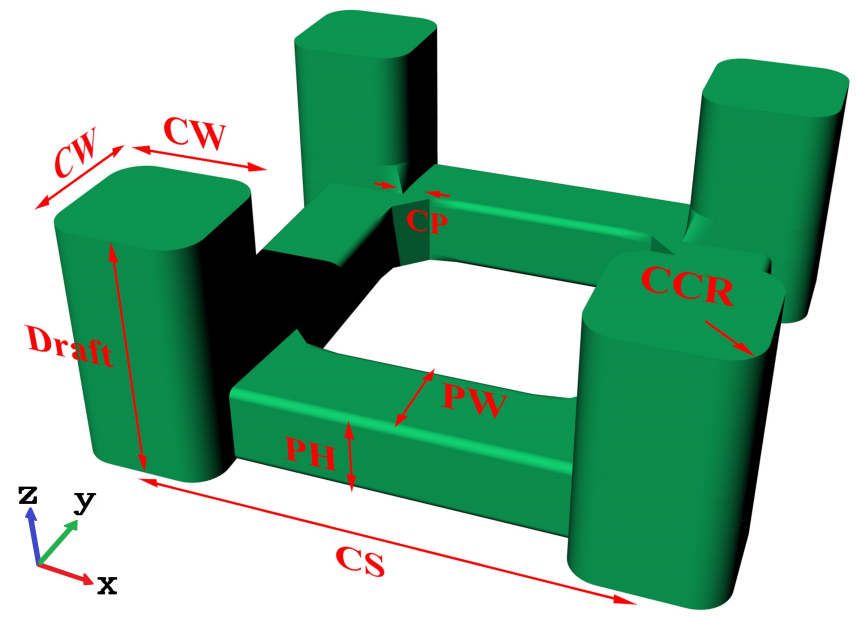

Figure 1: Definition of the problem, coordinate systems and main particulars

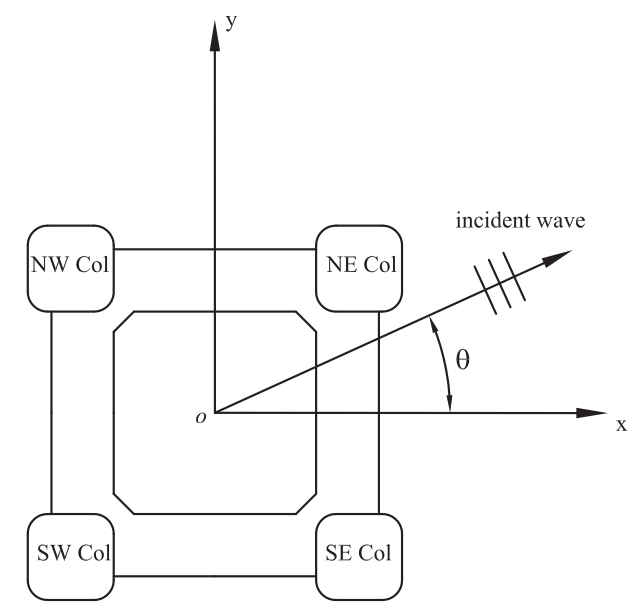

Figure 2: Definition of incident wave heading (Plan View) 
motion by using the aforementioned assumptions so that the fluid velocity can be expressed as the gradient of a potential function. The total velocity potential $\Phi(x, y, z, t)$ can be written in the following manner (Newman, 1977)

$$
\Phi(x, y, z, t)=\Phi_{I}(x, y, z, t)+\Phi_{D}(x, y, z, t)+\Phi_{R}(x, y, z, t)
$$

where $\Phi_{I}(x, y, z, t)$ represents a velocity potential due to incident wave; $\Phi_{D}(x, y, z, t)$ and $\Phi_{R}(x, y, z, t)$ denote the disturbance velocity potential due to wave diffraction and radiation, respectively. All the velocity potentials satisfy the Laplace equation. Appropriate body boundary condition, free surface boundary condition, and far-field radiation condition should be satisfied to complete the boundary value problem.

By assuming the amplitude of incident wave is small and the body motion is stable, all the velocity potentials can be written in a complex form as follows

$$
\Phi(x, y, z, t)=\operatorname{Re}\left[\phi(x, y, z) e^{-i \omega t}\right]
$$

where $\phi(x, y, z)$ is the spatial velocity potential and $\omega$ is the incident wave frequency. We denote $\phi_{j}(j=$ $1,2, \ldots, 6)$ and $\phi_{D}$ as the spatial radiation and diffraction velocity potentials, respectively. $\phi_{I}$ is the spatial velocity potential for an incident wave of the unit amplitude.

By using Eqn.(2), the boundary value problem can be further simplified to a time-independent one, which can be solved in the frequency domain. This type of BVP is solved by using a boundary integral method for both radiation and diffraction problems. Once the $\phi_{j}$ and $\phi_{D}$ are computed, the hydrodynamic pressure acting on the floating structure can be evaluated based on the Bernoulli's equation. As a result, the first-order wave exciting force can be obtained by integrating the hydrodynamic pressure over the mean wetted hull surface, which is expressed as

$$
F_{e x}=\operatorname{Re}\left[\rho i \omega \zeta e^{-i \omega t} \iint_{S_{B}}\left(\phi_{I}+\phi_{D}\right) n_{j} d s\right]
$$

where $\phi_{I}$ and $\phi_{D}$ are spatial velocity potentials for incident and diffracted waves, respectively; $\zeta$ is the amplitude of incident wave; $S_{B}$ is the mean wetted hull surface; $n_{j}(j=1,2, \ldots, 6)$ is the unit normal vector at the hull surface. After solving the radiation problem, the added mass and damping coefficients can be computed by

$$
\omega^{2} \mu_{k j}+i \omega \lambda_{k j}=\rho i \omega \iint_{S_{B}} \phi_{j} n_{k} d s
$$

where $\mu_{k j}$ and $\lambda_{k j}$ represent added mass and wave radiation damping, respectively; $\phi_{j}$ is the spacial radiation velocity potential due to a forced motion in $j t h$ mode.

\subsection{Potential flow theory (Panel model)}

In order to solve the boundary value problem by using boundary element method (BEM), the mean submerged hull surface has to be panelized. A typical panel model is illustrated in Figure 3. The average mesh size is 2 meters and the total number of panels is $N=7104$. As only the first-order velocity potential has to be solved, the calm water surface does not need to be meshed. Different mesh sizes have been selected for convergence test, which will be presented and discussed in Section 3. 


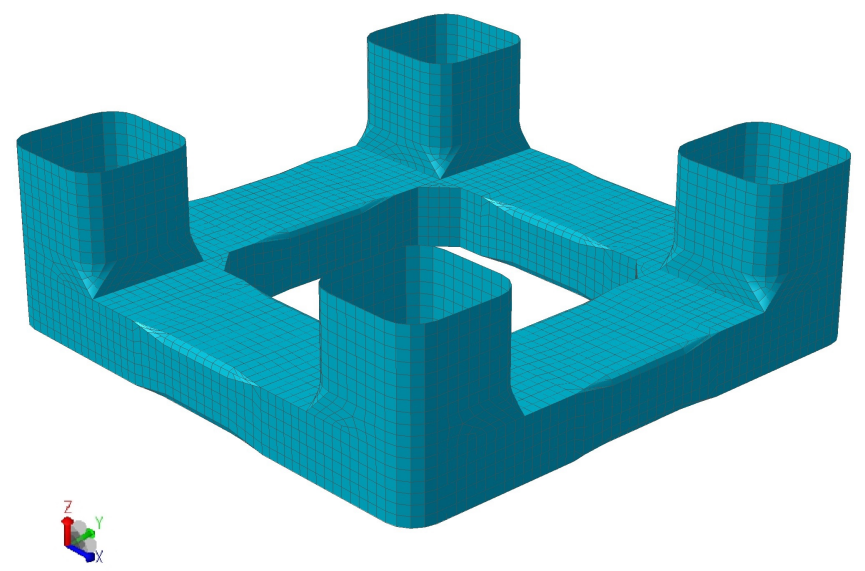

Figure 3: Panelization on the wetted hull surface, mesh size $=2 \mathrm{~m}$, number of panels $N=7104$

\subsection{Viscous effects (Morison model)}

Since the wave diffraction effect is trivial for small-scale structure, usually the Morison equation is employed to compute the wave-induced force (including inertia force and drag force) on small-scale structure, i.e. mooring lines, tendons and risers. In addition, Morison equation can also be applied to compute the drag forces on the columns and pontoons. As the floating structure may undergo large amplitude motion, it is necessary to consider the relative motion between the floating body and fluid particles. Thus, a generalized Morison equation should be adopted and it can be written as

$$
F=C_{M} \rho V \dot{u}-C_{a} \rho V \ddot{\xi}+\frac{1}{2} C_{d} \rho A(u-\dot{\xi})|(u-\dot{\xi})|
$$

where $C_{a}$ is the added mass coefficient; inertia coefficient $C_{M}=C_{a}+1 ; C_{d}$ is the drag coefficient; $V$ is the volume of the body; $A$ is the projected area matrix of the body; $u$ is the fluid particle velocity; $\xi$ is the motion amplitude of the body. In fact, the first term in Eqn.(5) represents Froude Krylov force and the third term is the drag force. It should be noted that $C_{d}$ should be determined based on the shape of cross section of the structure (DNV-RP-C205, 2007). The added mass for the large-scale components (columns and pontoons) is computed by using the panel method in context of potential flow theory. In addition, the drag force is nonlinear with respect to the fluid particle velocity. In order to compute the motion responses in frequency domain, it is necessary to perform linearizations (WADAM, 2005). The nonlinear drag force can be linearized based on the amplitude of motion response. The linearized drag force can be computed by

$$
F_{d}=\frac{1}{2} C_{d} \rho A \frac{8}{3 \pi} V_{\max }(u-\dot{\xi})=B_{v}(u-\dot{\xi})
$$

where $B_{v}$ is the linearized viscous damping coefficients; $V_{\max }$ is a linearizing velocity amplitude. It should be noted that a few iterations have to been performed to reach a converged linearized damping coefficient.

\subsection{Equation of motion in frequency domain}

The equation of motion for a floating structure in frequency domain can be written as

$$
\left[-\omega^{2}(M+\mu(\omega))-i \omega\left(\lambda(\omega)+B_{v}\right)+C+C_{e}\right] X(\omega, \theta)=F_{e x}(\omega, \theta)
$$


where $X$ is the amplitude of motion, including translational models $\vec{X}_{T}\left(X_{1}, X_{2}, X_{3}\right)$ and rotational modes $\vec{X}_{R}\left(X_{4}, X_{5}, X_{6}\right) ; M$ is the mass/inertia matrix of the floating structure. $\mu$ and $\lambda$ are the added mass and radiation damping coefficient, respectively; $B_{v}$ is the linearized viscous damping matrix. $C$ and $C_{e}$ are the hydrostatic matrix and the external restoring matrix of a mooring system, respectively. $F_{e x}$ is the wave exciting force per unit wave amplitude, depending on incident wave frequency $\omega$ and wave heading angle $\theta$.

The first-order motion response amplitude operators (RAOs) in regular waves can be computed through solving Eqn.(7). By using the obtained RAOs together with an irregular wave spectrum, the motion response spectrum can be evaluated by

$$
S_{R}(\omega, \theta)=|H(\omega, \theta)|^{2} S_{\zeta}(\omega)
$$

where $S_{R}$ is the response spectrum. $S_{\zeta}(\omega)$ is the irregular wave spectrum. $H$ is a transfer function, which is the RAO in this case. The root mean square (RMS) of the motion responses in irregular waves is computed by

$$
\sigma^{2}=\int_{-\pi / 2}^{\pi / 2} d \beta \int_{0}^{\infty}|H(\omega, \theta)|^{2} S_{\zeta}(\omega) f(\beta) d \omega
$$

where $f(\beta)$ is a wave spreading function only for short-crested waves, representing the directional distribution of energy in the waves, and is defined in the following way

$$
f(\beta)= \begin{cases}\frac{\int_{\beta-\delta / 2}^{\beta+\delta / 2} \cos ^{n} x d x}{\delta \int_{-\pi / 2}^{\pi / 2} \cos ^{n} x d x} & \text { for }-\pi / 2<\beta<\pi / 2 \\ 0 & \text { for otherwise }\end{cases}
$$

where $\beta$ represents the angle of the elementary waves relative to the main direction $\theta$ of the shorted-crested wave system. $\delta$ is the wave direction spacing and set to $15^{\circ}$. The larger the value of $n$, the more sharp is the distribution function and the more concentrated is the directional energy distribution. $n$ is set to 2 in the present study.

In this paper, JONSWAP wave spectrum is adopted, which can be written as

$$
S_{\zeta}(\omega)=\frac{\alpha g^{2}}{\omega^{5}} \exp \left(-1.25\left(\frac{\omega_{p}}{\omega}\right)^{4}\right) \gamma^{\exp \left(-\frac{\left(\omega-\omega_{p}\right)^{2}}{2 \sigma^{2} \omega_{p}^{2}}\right)}
$$

where $\omega_{p}$ is the peak wave frequency; $\gamma$ is the wave peak enhancement factor; $g$ is gravitational acceleration. $\sigma$ is the wave peak shape factor, which is evaluated by

$$
\sigma= \begin{cases}0.07 & \text { for } \omega<\omega_{p} \\ 0.09 & \text { for } \omega>\omega_{p}\end{cases}
$$

and $\alpha$ is defined by

$$
\alpha=\left(\frac{H_{s} \omega_{p}^{2}}{4 g}\right)^{2} \frac{1}{0.065 \gamma^{0.803}+0.135}
$$

where $H_{s}$ is the significant wave height.

\subsection{Second-order mean drift forces}

After solving the first-order boundary value problem, the second-order forces can be further computed by using the first-order velocity potential and motion response RAOs. There are two approaches to evaluate the 
second-order mean drift forces. One is the direct pressure integration method by integrating the second-order pressure over the submerged hull surface. The other is the momentum conservation method, which is derived from the momentum balance. To achieve better performance for convergence, the momentum conservation method is adopted for the computations (Newman, 1974; Lee, 1999)

\subsection{Wave elevation and airgap}

One of the key design and optimization criteria for a SEMI FPU is the airgap, which is defined as the minimum distance between water surface and bottom of the deck supported by the four columns. Hence, the airgap is related to the total wave elevation, which is the summation of the incident, diffracted and radiated waves. The minimum airgap $A G_{\min }$ at a point $\vec{x}(x, y, z)$ underneath deck bottom can be evaluated by

$$
A G_{\min }=A G_{s}-Z_{\max }
$$

where $A G_{s}$ denotes the static airgap, which is equal to the freeboard (FB) of the hull. $Z_{\max }$ represents the relative wave surface elevation with respect to the platform. It can be computed by

$$
Z_{\max }=\eta-\left(X_{3}-X_{5} x+X_{4} y\right)
$$

where $\eta$ is the wave elevation including the incident, diffracted and radiated waves. $\vec{X}_{R}\left(X_{4}, X_{5}, X_{6}\right)$ are the motion amplitudes in rotational modes. It should be noted that the relative motion includes wave frequency and low frequency components. Only wave frequency component is considered in this study. The most probable minimum (MPM) airgap is obtained by assuming Rayleigh distribution for the relative wave elevation.

Based on Rayleigh distribution which assumes narrow-banded wave spectrum, the most probable largest response is given by

$$
A_{\max }=\sqrt{2 \sigma^{2} \ln \frac{D_{s}}{T_{A}}}
$$

where $\sigma$ is the root mean square of the responses in irregular waves. $D_{s}$ is the duration of short term sea state and set to 3 hours. $T_{A}$ is the mean-zero-upcrossing response period.

\section{Numerical Results}

\subsection{Convergence tests}

Convergence tests have been carried out for a typical SEMI FPU. The main particulars of the base SEMI FPU are listed in Table 1. The convergence of the numerical solutions with respect to the size of panels are presented in Figure 4. Four sets of panelizations are selected for convergence tests. As shown in the plots, the predicted hydrodynamic coefficients, including heave added mass $\left(\mu_{33}\right)$ and damping coefficients $\left(\lambda_{33}\right)$, wave exciting forces and the motion responses (RAOs) converge as the panel size decreases. Furthermore, excellent convergence performance is found even around the resonances, which confirms that the present numerical model can well predict the hydrodynamic behavior of a floating semi-submersible. Therefore, by compromising the accuracy and efficiency, the panel size of 3 meters is adopted for the following computations.

As shown in Figure 4, the added mass in heave $\mu_{33}$ approaches to a constant value when the forced motion period goes up to infinity. Meanwhile, the heave damping coefficient drops to zero when wave frequency 
Table 1: Main particulars of a base SEMI FPU

\begin{tabular}{lccc}
\hline Description & Unit & Symbol & Value \\
\hline Length & $\mathrm{m}$ & $\mathrm{L}$ & 94.72 \\
Beam & $\mathrm{m}$ & $\mathrm{B}$ & 94.72 \\
Draft & $\mathrm{m}$ & Draft & 31.0 \\
Freeboard & $\mathrm{m}$ & $\mathrm{FB}$ & 20.0 \\
Number of columns & $/$ & $/$ & 4 \\
Column width & $\mathrm{m}$ & $\mathrm{CW}$ & 21.76 \\
Column length & $\mathrm{m}$ & $\mathrm{CL}$ & 21.76 \\
Column spacing (center to center) & $\mathrm{m}$ & $\mathrm{CS}$ & 72.96 \\
Column corner radius & $\mathrm{m}$ & $\mathrm{CCR}$ & 5.045 \\
Pontoon width & $\mathrm{m}$ & $\mathrm{PW}$ & 21.76 \\
Pontoon height & $\mathrm{m}$ & $\mathrm{PH}$ & 10.88 \\
Pontoon corner radius & $\mathrm{m}$ & $\mathrm{PCR}$ & 1.28 \\
Width of cakepiece & $\mathrm{m}$ & $\mathrm{CP}$ & 5.12 \\
Displacement & $\mathrm{metric}$ ton & $\Delta$ & 108,031 \\
Radius of gyration about x-axis & $\mathrm{m}$ & $R_{x x}$ & 34.68 \\
Radius of gyration about y-axis & $\mathrm{m}$ & $R_{y y}$ & 34.68 \\
Radius of gyration about z-axis & $\mathrm{m}$ & $R_{z z}$ & 39.23 \\
Transverse metacentric height & $\mathrm{m}$ & $G M_{T}$ & 1.0 \\
Longitudinal metacentric height & $\mathrm{m}$ & $G M_{L}$ & 1.0 \\
\hline & & &
\end{tabular}


approaches to zero or infinity. The surge exciting force reaches the maximum around wave period of 7 to 8 seconds, which causes a local hump in surge RAO in that particular range of wave periods. In fact, the surge hump is one of the key factors which causes the wave-induced fatigue of production or oil/gas export risers because the operational wave condition is concentrated on the range of those wave periods (API RP 2MET, 2014). Moreover, it is found that the heave exciting force reaches the maximum as the heave damping $\mu_{33}$ approaches the maximum. This can be explained by the Haskind relation (Newman, 1977). The heave damping coefficient drops to almost zero for wave period around 23 seconds, which is correlated with the minimum in the plot of the heave exciting force $F_{3}$. This particular wave period is called the cancellation period, where the wave exiting force reaches the minimum as the heave force acting on each pontoon cancels each other. Other cancellation periods can also be identified in the plot of wave exciting forces. As a result, the heave RAO has the minimums at those cancellation periods as shown in Figure 4(f).

\subsection{Wave exciting forces and RAOs in regular waves}

Figure 5 illustrates the wave exciting force/moment for sway, roll, pitch and yaw in four different wave headings including $0^{\circ}, 15^{\circ}, 30^{\circ}$ and $45^{\circ}$. As shown, the peak pitch moments at wave period around 11 seconds are very close for the four wave headings, and the yaw moments are nil at $0^{\circ}$ and $45^{\circ}$ wave headings. The complete six degrees of freedom response amplitude operators (RAOs) of a typical SEMI in regular waves are also computed. The numerical results are illustrated in Figure 6. As can be observed, the surge RAO has a hump (maximum) for wave periods around 8 seconds in $0^{\circ}$ wave heading. The heave RAO is nearly not affected by the wave heading. The heave hump amplitude, critical to the wave-induced fatigue for hang-off risers, is roughly 0.5 in a wave period around 17 to 18 seconds. The heave resonant period is around 25.5 seconds. The amplitude of heave resonant motion depends on sea state as the viscous damping, related with the sea state, can affect the solution significantly. In addition, yaw motions at both $0^{\circ}$ and $45^{\circ}$ are nil due to symmetry property. Further, the yaw motions are very similar at $15^{\circ}$ and $30^{\circ}$, since $15^{\circ}$ and $30^{\circ}$ wave headings share the same angle relative to $0^{\circ}$ and $45^{\circ}$, respectively.

\subsection{Motion responses in irregular waves}

The motion responses in irregular waves are also computed. 100-year hurricane wave condition in Gulf of Mexico is applied (API RP 2MET, 2014) for the analyses. JONSWAP spectrum is adopted as input irregular wave condition. Two sea states are adopted for analyses. One is the operational wave condition, the other one is the survival wave condition. The wave parameters for the two load cases are listed in Table 2. The motion response spectrums in long-crested waves are plotted in Figure 7. As presented, the motion responses in the survival condition are much higher than those in the operational condition. The peak frequencies of response spectrums in surge, heave and pitch in survival condition are lower than those in operational condition. The motion response spectrums in short-crested waves are plotted in Figure 8. The comparisons of surge, heave, pitch and yaw responses in long-crested and short-crested waves are listed in Table 3. As shown, surge, pitch and yaw motion responses in short-crested waves are much smaller than those in long-crested waves, while heave motion responses in short and long-crested waves are almost the same (about one percent of difference) due to its insensitivity of wave direction. 

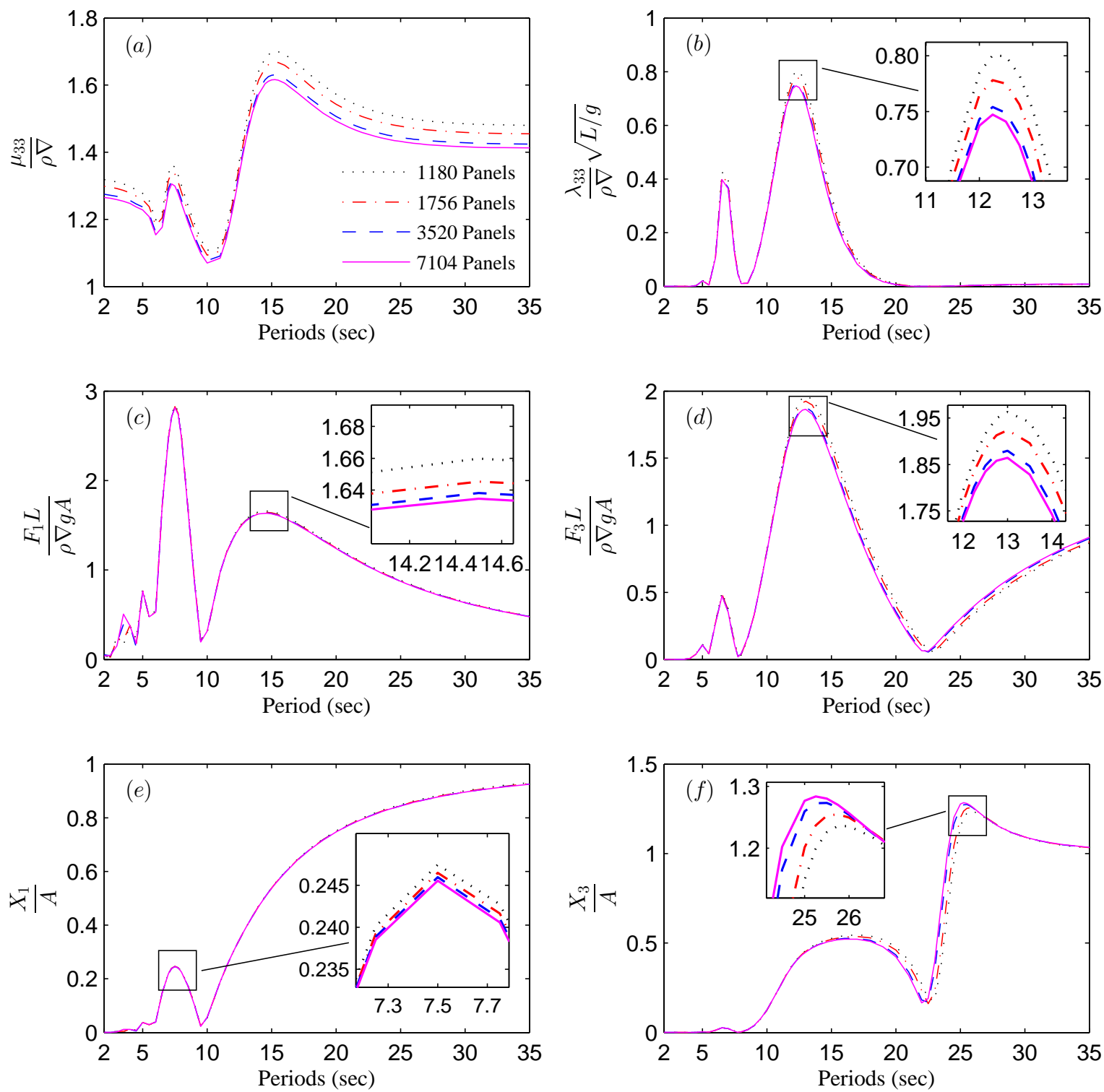

Figure 4: Convergence of hydrodynamic coefficients, wave exciting forces and RAOs by adopting different mesh sizes, four sets of panelizations: (a) Added mass in heave due to forced heave motions; (b) Wave radiation damping in heave due to forced heave motions; (c) Wave exciting force in surge; (d) Wave exciting force in heave; (e) Surge RAO; (f) Heave RAO. Wave heading $\theta=0^{\circ}$. $A$ is the amplitude of incident wave. Main particulars of the hull are listed in Table 1.

Table 2: Wave parameters for operational and survival conditions

\begin{tabular}{lccccc} 
Condition & $H_{s}(m)$ & $T_{p}(s)$ & $\gamma$ & $\sigma_{a}$ & $\sigma_{b}$ \\
\hline Operational & 8.2 & 11.8 & 1.5 & 0.07 & 0.09 \\
Survival & 15.8 & 15.4 & 2.4 & 0.07 & 0.09 \\
\hline
\end{tabular}



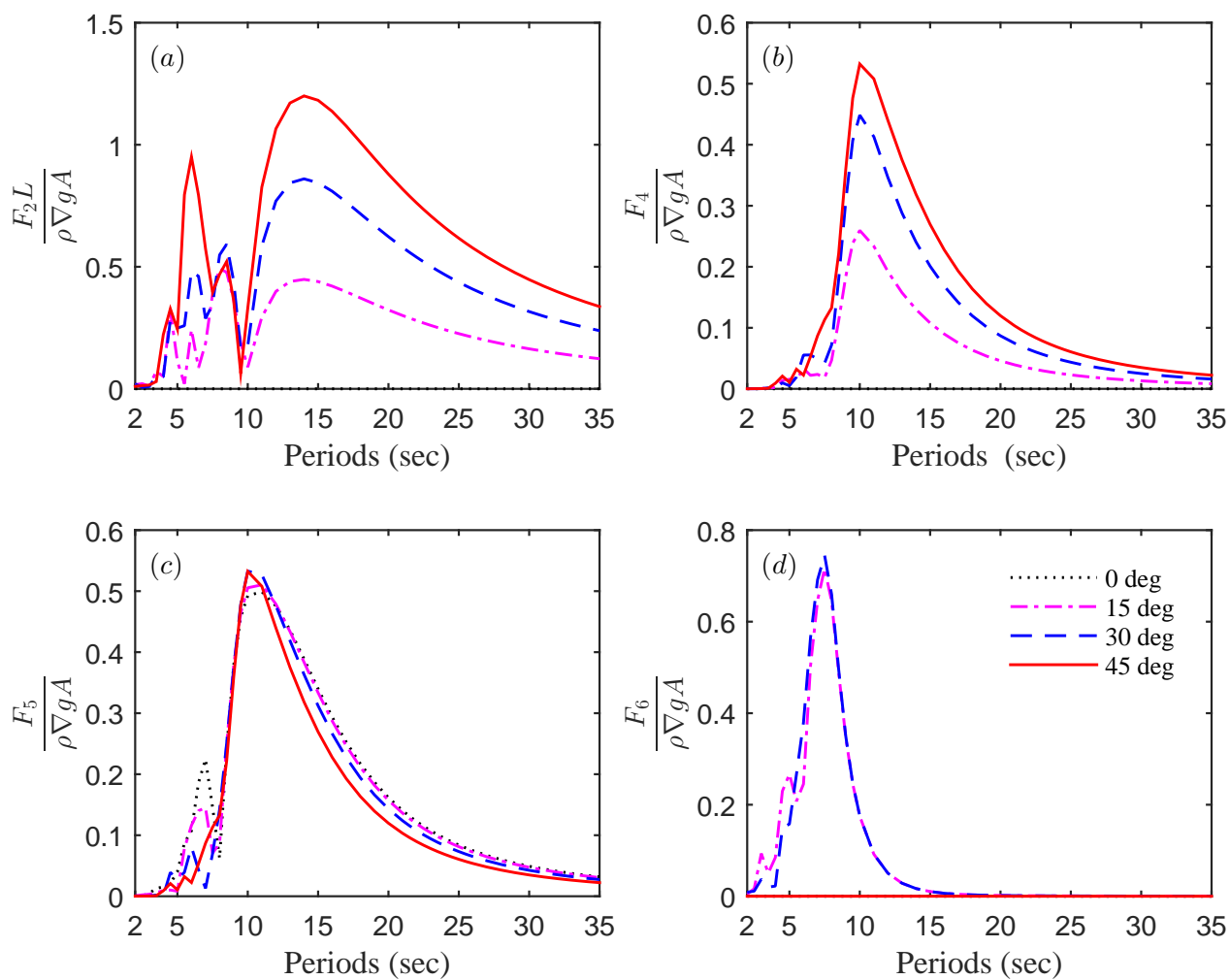

Figure 5: Wave exciting force/moment in regular waves with different wave headings: (a) Sway; (b) Roll; (c) Pitch; (d) Yaw. Main particulars of the hull are listed in Table 1.

Table 3: Root mean squares of motion responses in irregular waves

\begin{tabular}{llcccc}
\hline Wave & Condition & $\sigma_{X_{1}}(m)$ & $\sigma_{X_{3}}(\mathrm{~m})$ & $\sigma_{X_{5}}(\mathrm{rad})$ & $\sigma_{X_{6}}(\mathrm{rad})$ \\
\hline \multirow{2}{*}{ Long-crested } & Operational & $7.18 \mathrm{E}-02$ & $7.53 \mathrm{E}-02$ & $1.26 \mathrm{E}-03$ & $4.06 \mathrm{E}-04$ \\
& Survival & $1.22 \mathrm{E}-01$ & $1.09 \mathrm{E}-01$ & $1.38 \mathrm{E}-03$ & $2.53 \mathrm{E}-04$ \\
\hline \multirow{2}{*}{ Short-crested } & Operational & $6.19 \mathrm{E}-02$ & $7.41 \mathrm{E}-02$ & $1.21 \mathrm{E}-03$ & $3.25 \mathrm{E}-04$ \\
& Survival & $1.06 \mathrm{E}-01$ & $1.08 \mathrm{E}-01$ & $1.29 \mathrm{E}-03$ & $2.03 \mathrm{E}-04$ \\
\hline
\end{tabular}



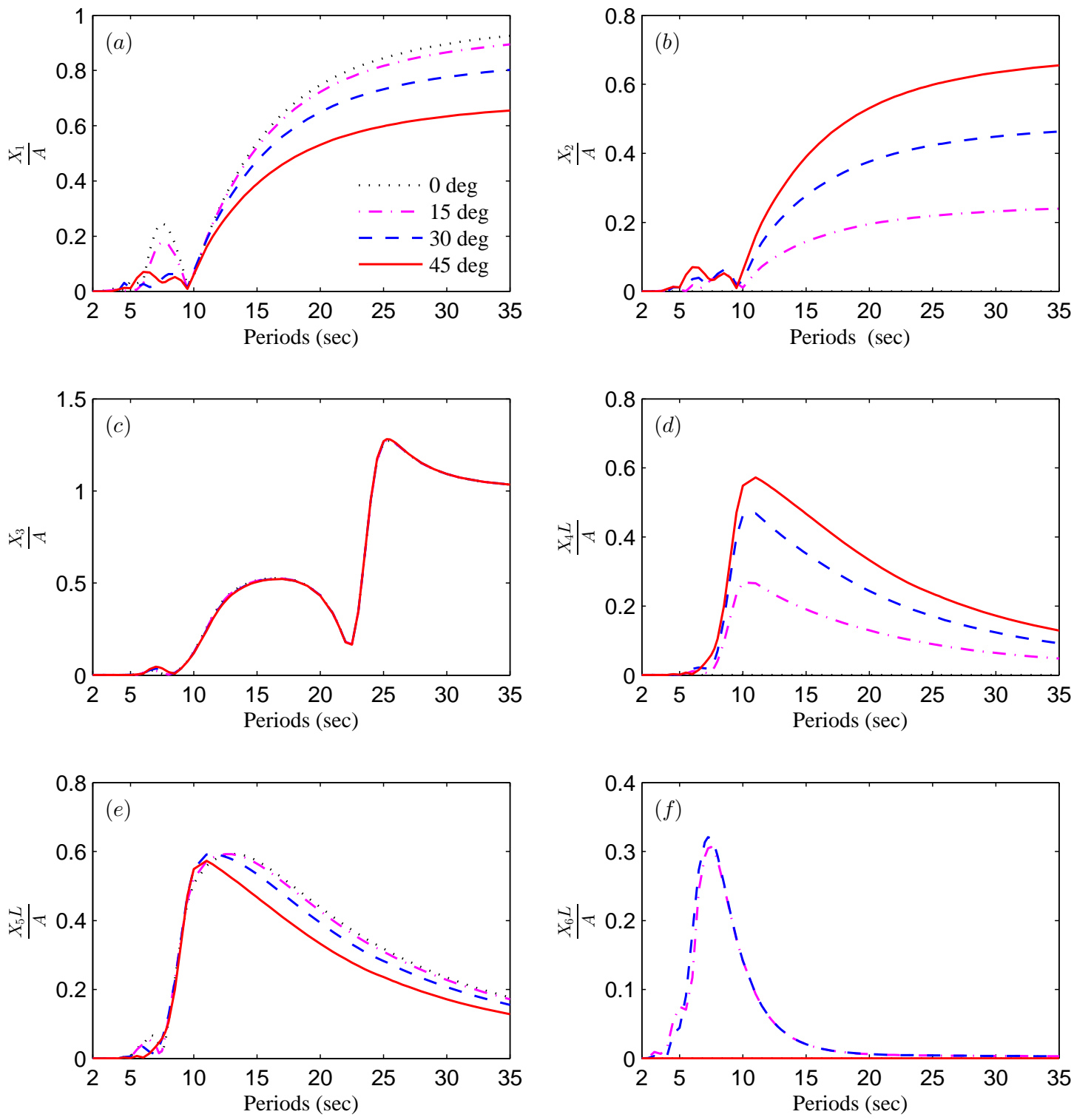

Figure 6: RAOs in regular waves with different wave headings: (a) Surge motion; (b) Sway motion; (c) Heave motion; (d) Roll motion; (e) Pitch motion; (f) Yaw motion. Main particulars of the hull are listed in Table 1. 

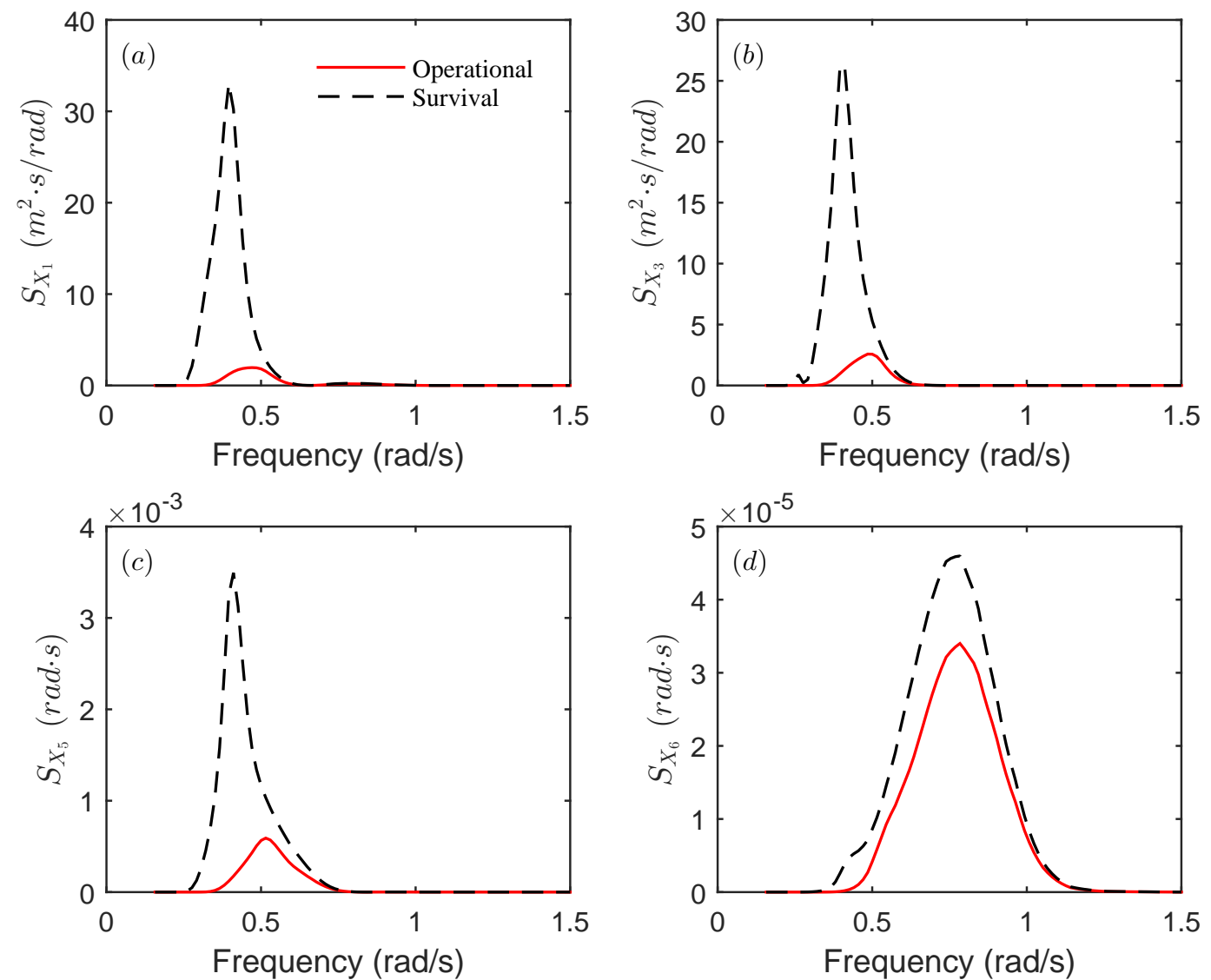

Figure 7: Response spectrums in long-crested waves for operational and survival conditions, wave heading $\theta=0^{\circ}$ : (a) Surge; (b) Heave; (c) Pitch; (d) Yaw (wave heading $\theta=30^{\circ}$ ). 

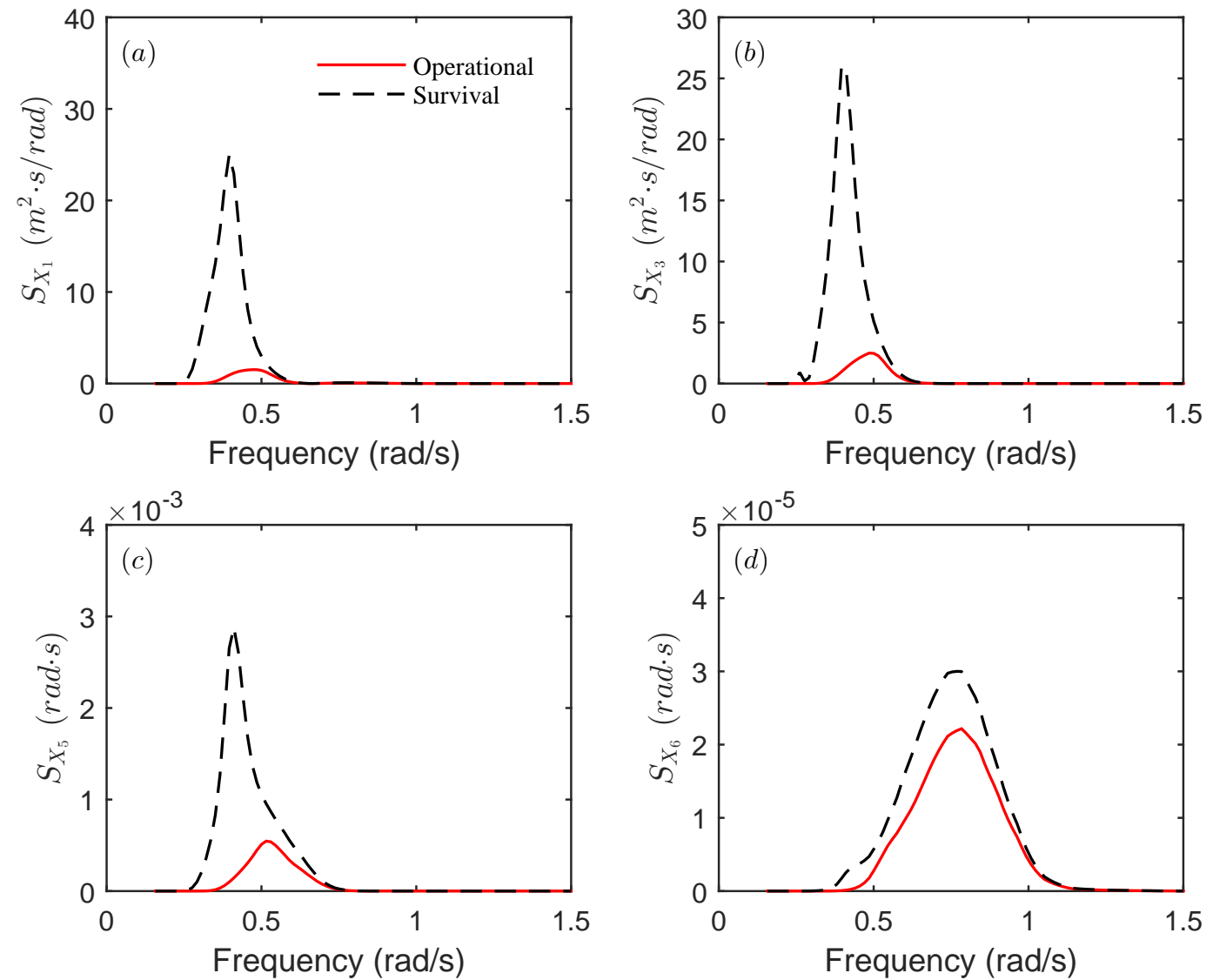

Figure 8: Response spectrums in short-crested waves for operational and survival conditions, wave heading $\theta=0^{\circ}$ : (a) Surge; (b) Heave; (c) Pitch; (d) Yaw (wave heading $\theta=30^{\circ}$ ). 

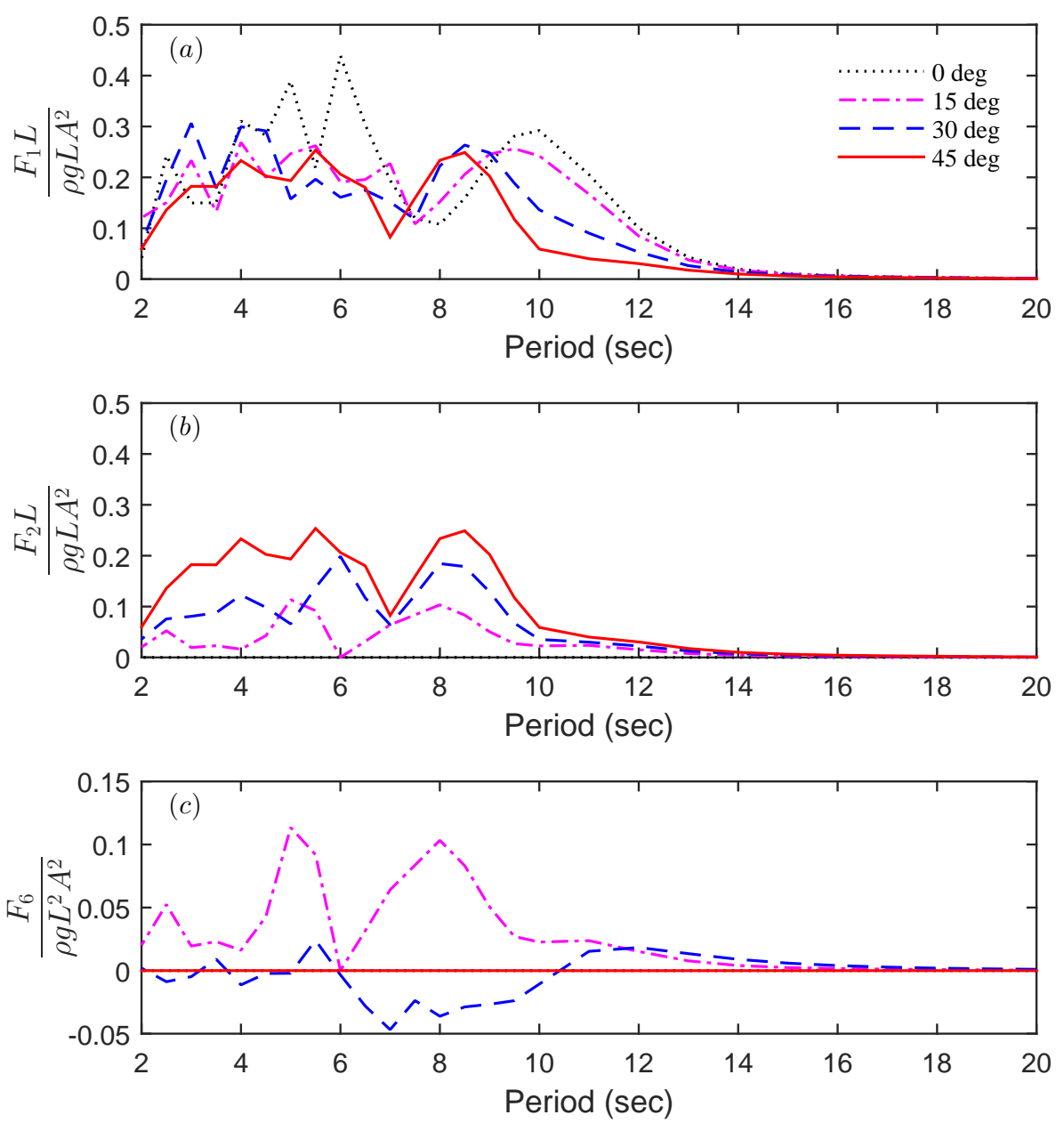

Figure 9: Second-order mean drift force with different wave headings: (a) Surge; (b) Sway; (c) Yaw. Hull main particulars are listed in Table 1.

\subsection{Mean drift forces}

The second-order mean drift forces are computed based on the momentum conservation method and the numerical results are illustrated in Figure 9. The drift forces in surge, sway and yaw are all presented for four different wave headings $\theta=0^{\circ}, 15^{\circ}, 30^{\circ}$, and $45^{\circ}$. As illustrated, the mean drift forces show high oscillations in the high frequency (low wave periods) region. In addition, the maximum mean drift yaw moment occurs in $15^{\circ}$ wave heading.

\subsection{Wave elevation and airgap}

In order to examine the characteristics of diffracted and radiated wave field inside the moonpool, which is critical to the evaluation of the probability of deck slamming, the distribution of the wave elevations is computed and analyzed.

The convergence analysis for airgap is performed at two different locations for four different wave headings with four sets of panelizations. As presented in Figure 10, the predicted airgaps converge as the number of panels increases over 3520. Therefore, the panel size of 3 meters (3520 panels) is adopted for airgap computations.

The convergence analysis of probes' smallest distance to column is also carried out. Thirteen probes are placed at $y=36.48$ meters with the interval of 0.2 meter, among which the closest to the column is 0.6 meter. 

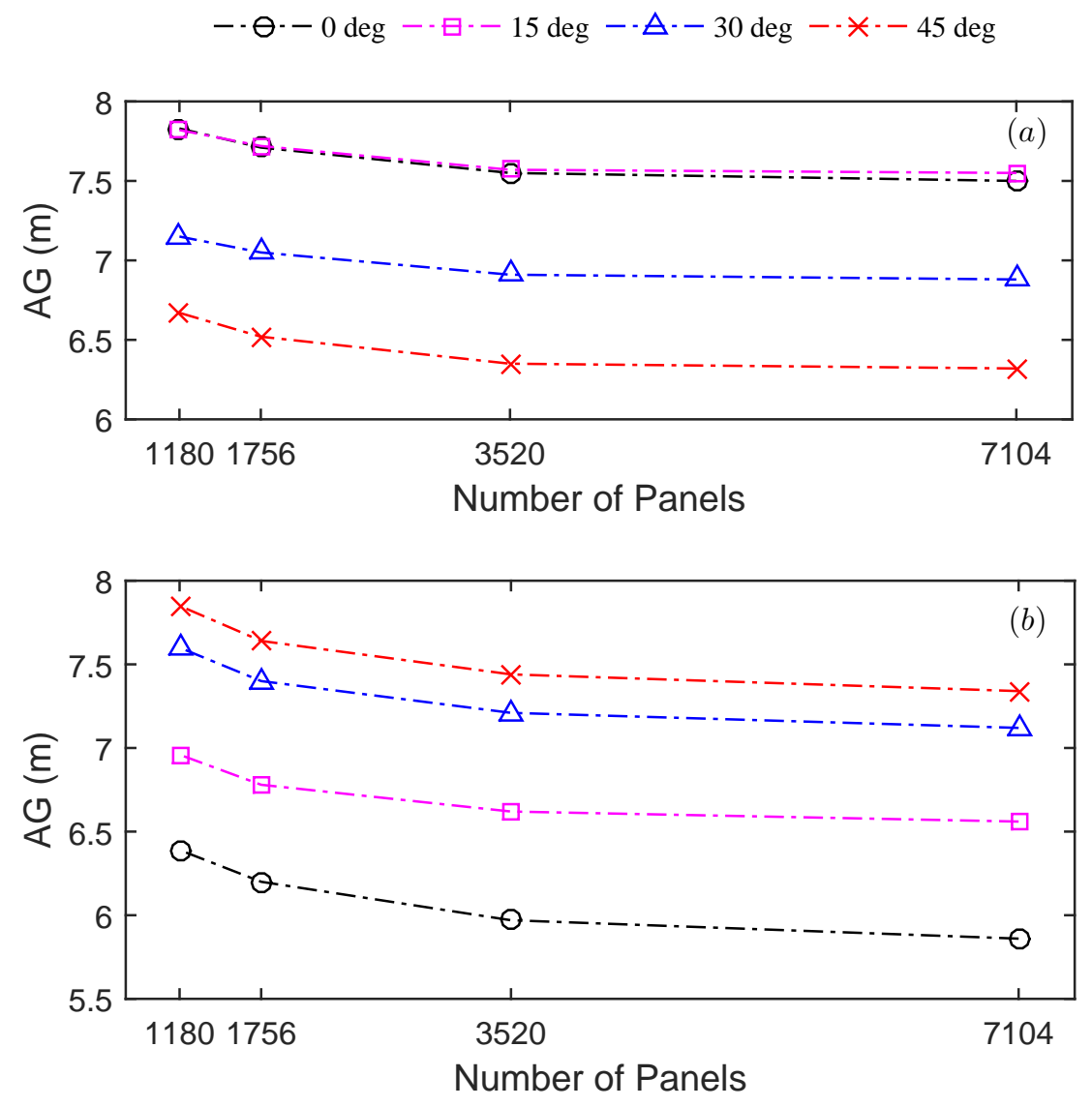

Figure 10: Convergence of airgap with different wave headings, $H_{s}=15.8 \mathrm{~m} ; T_{p}=15.4$ sec; peak enhancement factor $\gamma=2.4 ;(\mathrm{a})$ Probe at $(25.52 \mathrm{~m}, 25.52 \mathrm{~m}, 0 \mathrm{~m})$; (b) Probe at $(23.4 \mathrm{~m}, 36.48 \mathrm{~m}, 0 \mathrm{~m})$.

The airgaps of these probes in irregular long-crested waves are illustrated in Figure 11. As shown, the smallest airgap occurs at $2 \sim 2.4$ meters away from the column. Therefore, the innermost probes are set 2.2 meters away from columns. The distribution of wave probes for airgap computations is illustrated in Figure 12. The wave scattering is investigated in both regular and irregular wave conditions.

First, the case of regular waves is studied. The selected wave period is 15.4 seconds. The total wave elevations including incident, diffracted and radiated waves are plotted in Figure 13 for four different wave headings. As illustrated in Figure 13(b), the maximum wave amplitude is 1.213 and it occurs in wave heading of $15^{\circ}$ near the Northeast (NE) column at point $(23.4 \mathrm{~m}, 30.65 \mathrm{~m}, 0 \mathrm{~m})$. This can be attributed to the fact that the closer it is to the wall, the stronger wave diffraction is.

Second, the wave scattering in irregular waves is also investigated. Figure 14 shows the contour of most probable maximum (MPM in 3-hour simulation based on Rayleigh distribution) wave elevations in long-crested waves. As shown, the most probable maximum wave elevation is 19.7 meters and it occurs at the first point in the diagonal line next to the NE column in wave heading $\theta=45^{\circ}$. The difference between the results in regular and irregular waves reflects that the worst wave heading for wave elevation is related with wave periods. Thus, a few other irregular wave spectrums with different peak wave periods $T_{p}$ are tested. It is confirmed that the maximum wave elevation occurs in the same wave heading $\theta=45^{\circ}$ for peak wave periods ranging from 13 to 15 seconds, and also at the same point in the diagonal line. This particular point is denoted as WP45 (25.52 


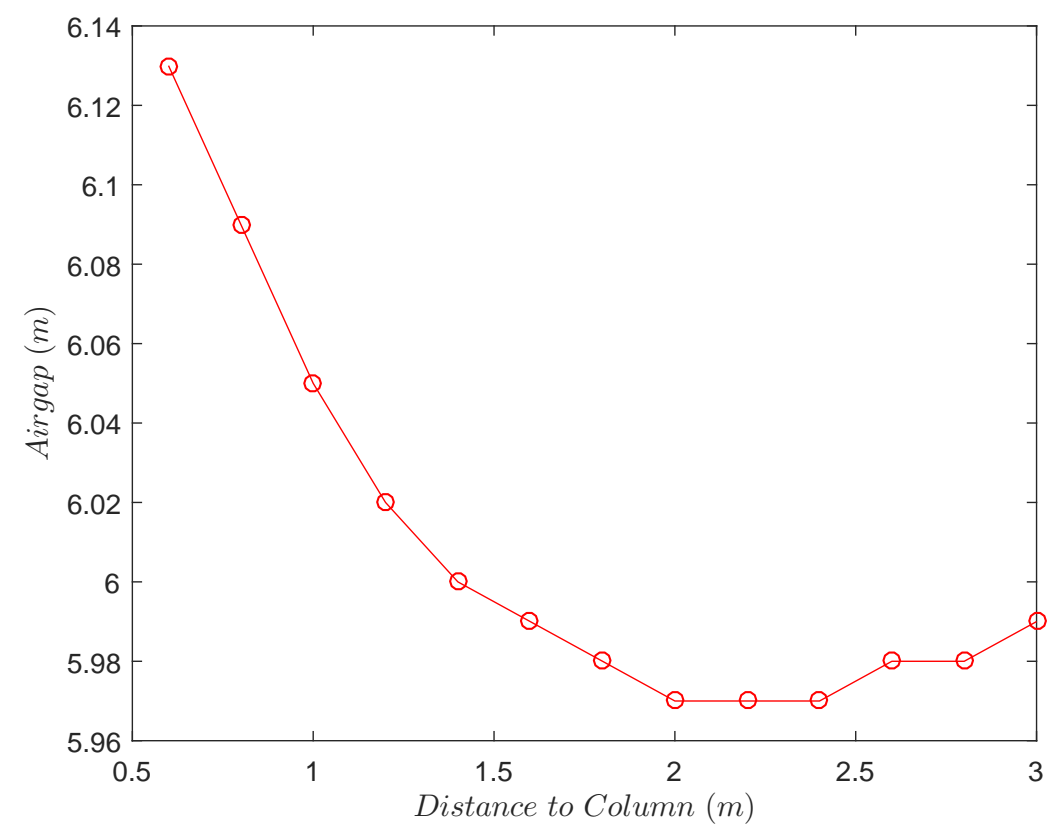

Figure 11: Convergence of airgap's distance to column, $H_{s}=15.8 \mathrm{~m} ; T_{p}=15.4$ sec; peak enhancement factor $\gamma=2.4 ; \theta=0{ }^{\circ}$

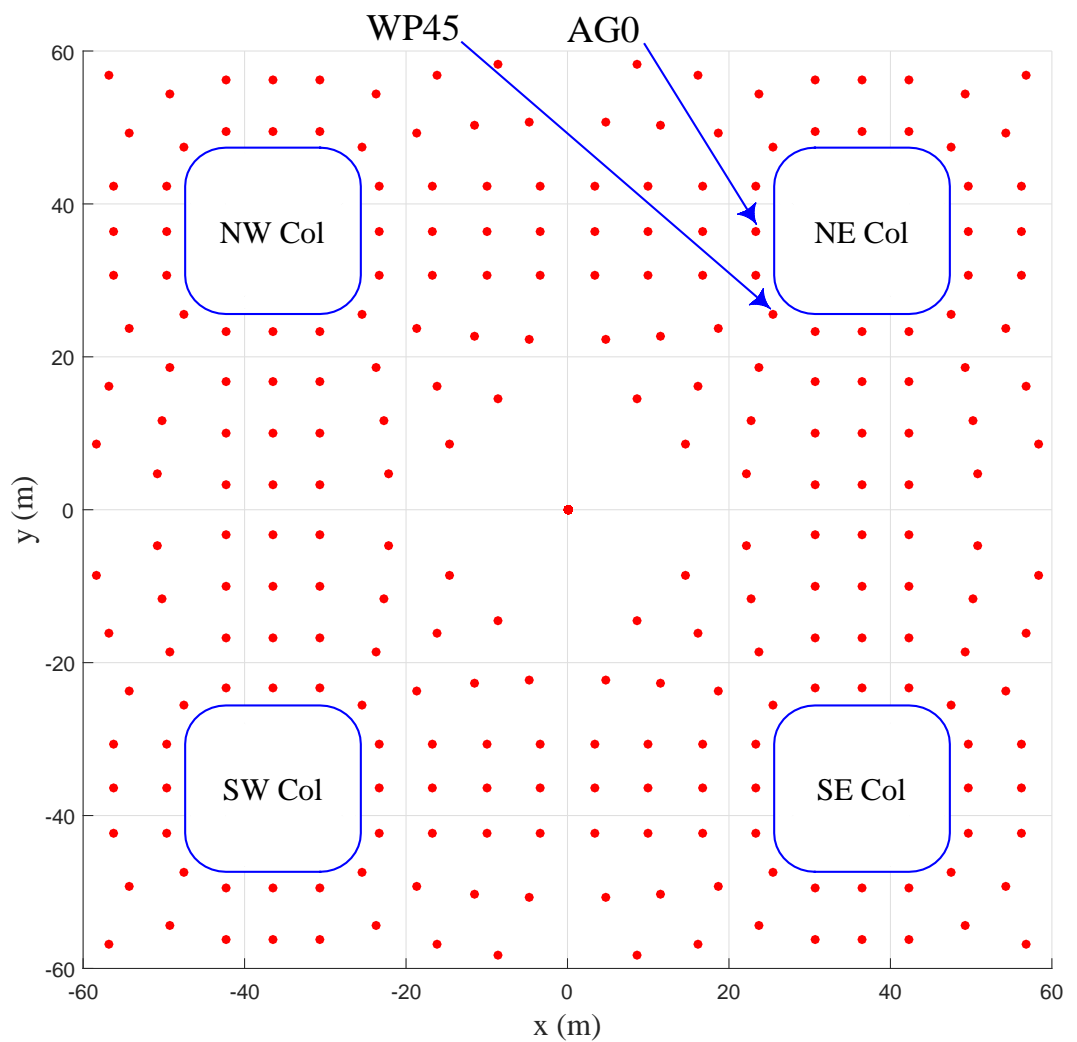

Figure 12: Location of probes (red points) for measuring of the wave elevations and airgaps (Plan View) 

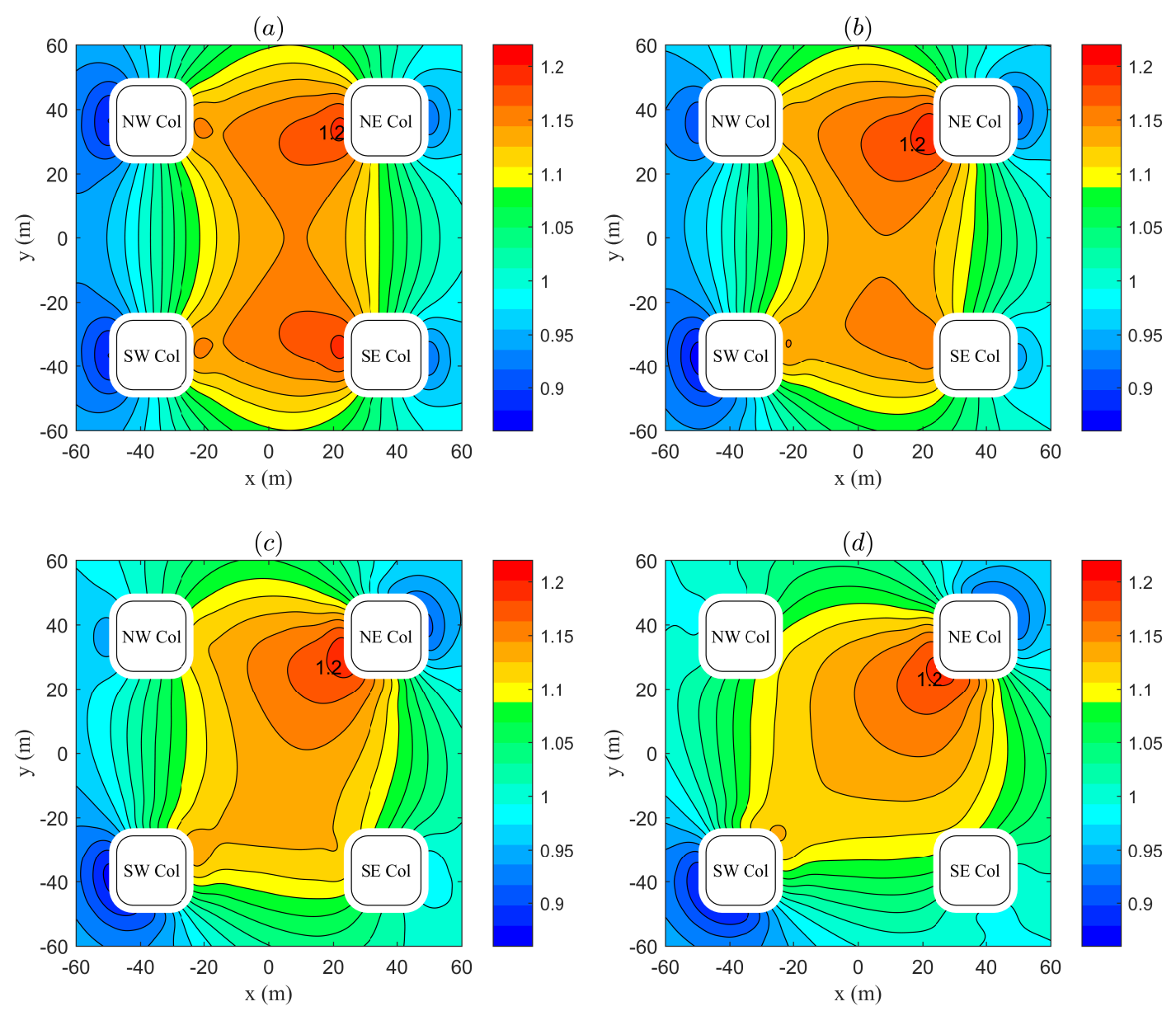

Figure 13: Contour of wave elevations in regular waves, wave period $T=15.4 \mathrm{sec},(\mathrm{a}) \theta=0^{\circ} ;$ (b) $\theta=15^{\circ} ;$ (c) $\theta=30^{\circ} ;(\mathrm{d}) \theta=45^{\circ}$. 

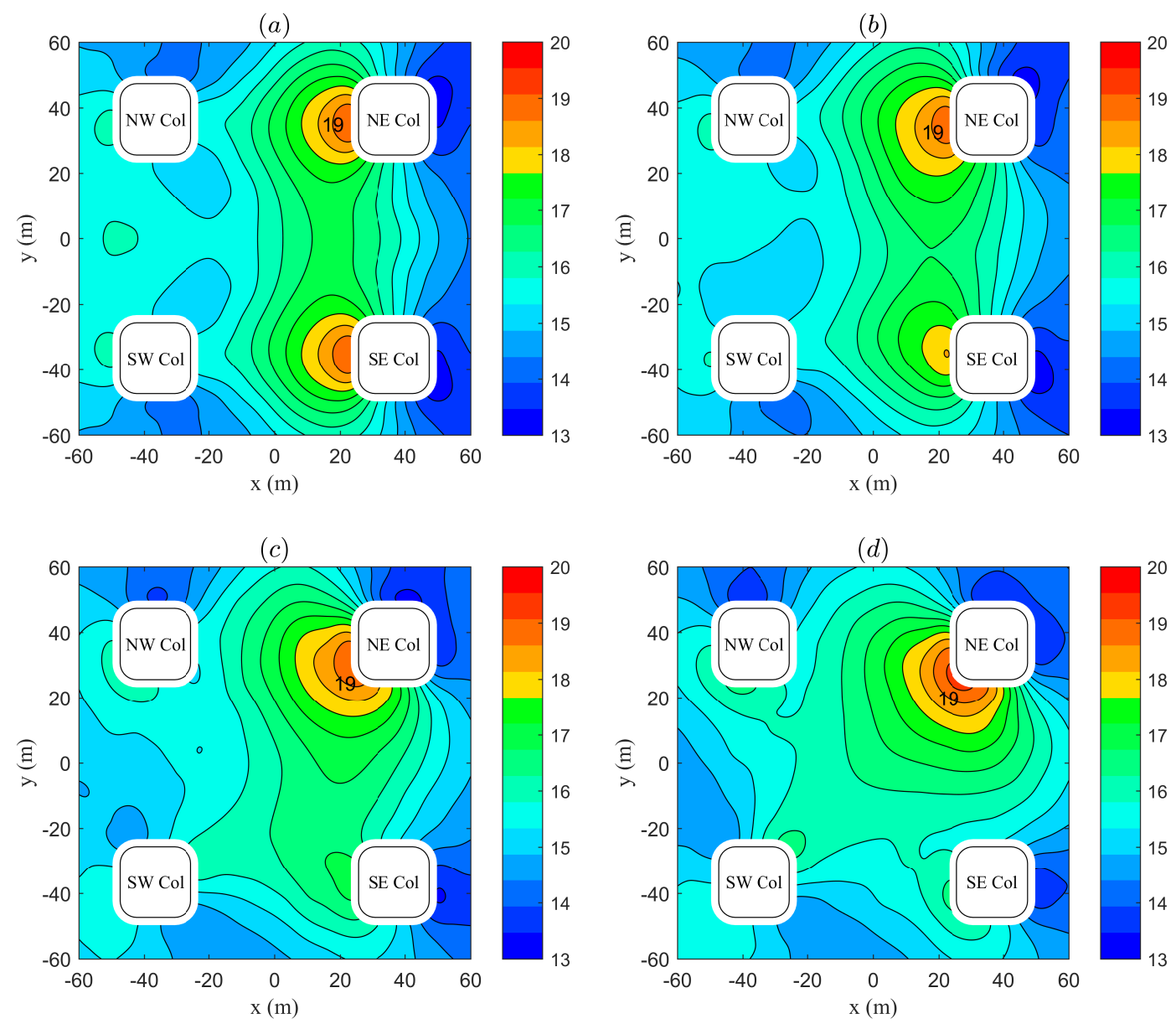

Figure 14: Contour of wave elevations in long-crested waves, $H_{s}=15.8 \mathrm{~m} ; T_{p}=15.4 \mathrm{sec}$; peak enhancement factor $\gamma=2.4$. (a) $\theta=0^{\circ}$; (b) $\theta=15^{\circ}$; (c) $\theta=30^{\circ}$; (d) $\theta=45^{\circ}$.

$\mathrm{m}, 25.52 \mathrm{~m}, 0 \mathrm{~m})$.

The contour of airgaps in long-crested linear waves is plotted and illustrated in Figure 15. The motion responses of the FPU are included in the evaluation of airgaps. It should be noted that only wave frequency motion is considered here (low frequency motion will be included in the future study). It is found that the sum of the most probable maximum wave elevation and minimum airgap for each point is larger than static airgap, which indicates that motion responses of the FPU play a significant role in sustaining airgaps. As shown in Figure 15(d), the most probable minimum airgap is 5.43 meters in 100-year hurricane condition and it occurs in the diagonal line pointing to the SW column along the wave direction $\theta=45^{\circ}$, though the maximum wave elevation point is in the diagonal line pointing to the NE column. This reflects that the effect of motion responses at the minimum airgap point (AG45) is much weaker than the effect at WP45. The phase angles of wave elevation and vertical motion (combined of heave, roll and pitch motions) at AG45 and WP45 are illustrated in Figure 16. It shows that the wave elevation and vertical motion share almost the same phase angle at WP45 for wave period around 15 seconds, while they have approximate $0.25 \pi$ phase difference at AG45. Therefore, although the vertical motion at WP45 is smaller than that at AG45, the airgap at WP45 is increased greatly. We denote the worst airgap point in long-crested linear waves as AG45 (-56.89 m, -56.89 m, 

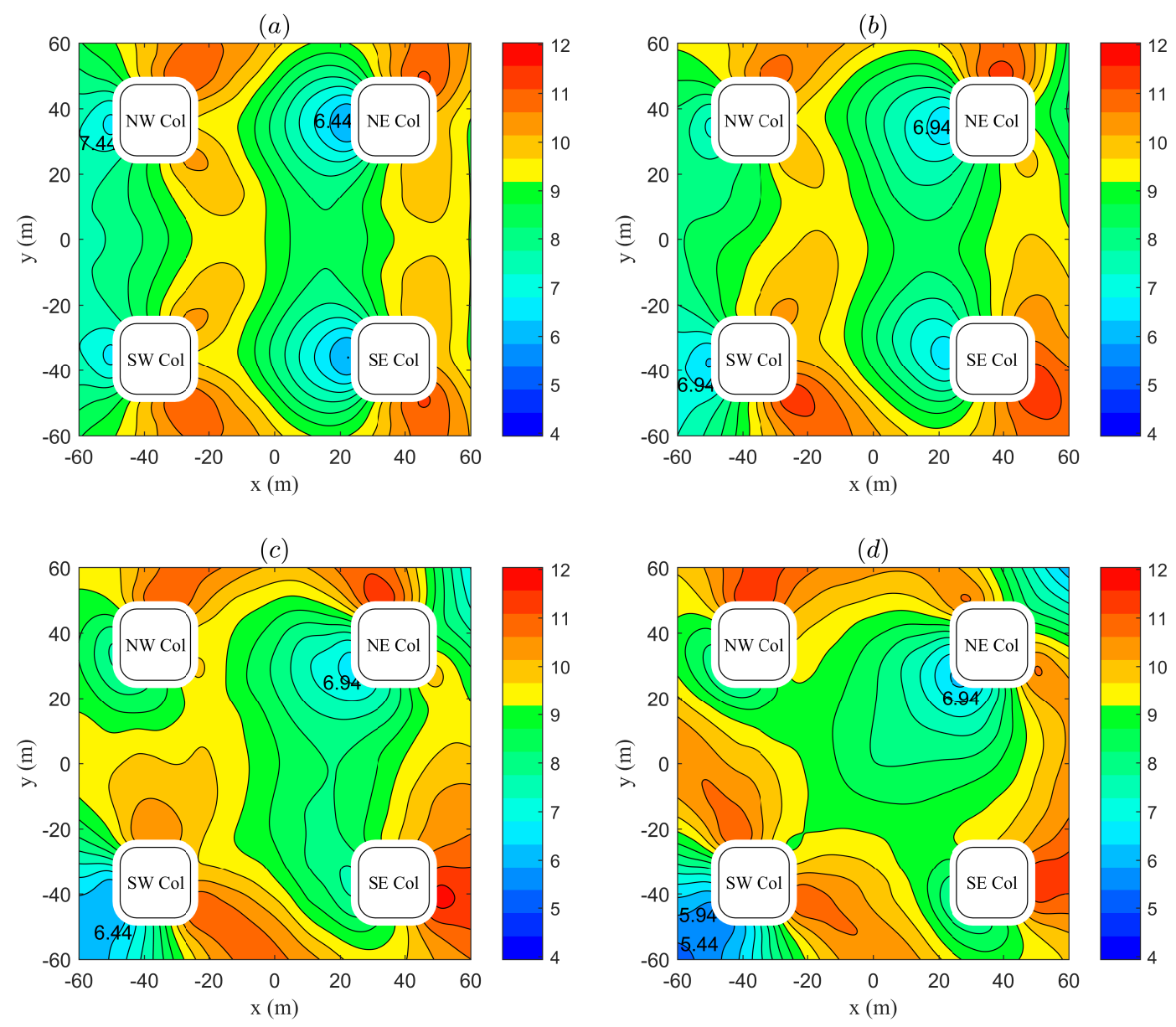

Figure 15: Contour of airgap in long-crested linear waves, $H_{s}=15.8 \mathrm{~m} ; T_{p}=15.4 \mathrm{sec}$; peak enhancement factor $\gamma=2.4$. (a) $\theta=0^{\circ}$; (b) $\theta=15^{\circ}$; (c) $\theta=30^{\circ}$; (d) $\theta=45^{\circ}$.

$0 \mathrm{~m})$.

The contour of airgaps in short-crested linear waves is plotted in Figure 17. Compared with the results in long-crested waves, the variation of airgap in concerned area is much smaller. The most probable minimum airgap is 7.05 meters and it occurs at point $(23.4 \mathrm{~m}, 30.65 \mathrm{~m}, 0 \mathrm{~m})$ near NE column in wave heading $\theta=15^{\circ}$.

The contour of airgaps in long-crested nonlinear waves is plotted in Figure 18. In order to account for wave nonlinearities, a wave amplification factor 1.2 is applied. As shown, the most probable minimum airgap is 2.16 meters and it occurs at the points at the left side of $\mathrm{NE}$ and $\mathrm{SE}$ columns in wave heading $\theta=0^{\circ}$. The worst airgap point near NE column is denoted as AG0 $(23.4 \mathrm{~m}, 36.48 \mathrm{~m}, 0 \mathrm{~m})$. Due to the nonlinear effect of waves, wave elevations have a greater influence than motion responses on airgaps so that the worst airgap occurs inside the square formed by four columns. It has been confirmed that the wave elevation and vertical motion share almost the same phase angle at both AG0 and WP45 in wave heading $\theta=0^{\circ}$ and $\theta=45^{\circ}$, respectively. However, the vertical motion at AG0 in $\theta=0^{\circ}$ is smaller than that at WP45 in $\theta=45^{\circ}$ because the vertical motion in wave heading $\theta=45^{\circ}$ combines heave, roll and pitch while it is only related with heave and pitch in $\theta=0^{\circ}$ since roll motion is zero. Therefore, the effect of motion responses at WP45 is stronger than that at AG0 on airgap. As nonlinear waves are more likely to happen in real sea condition, AG0 in nonlinear waves in 

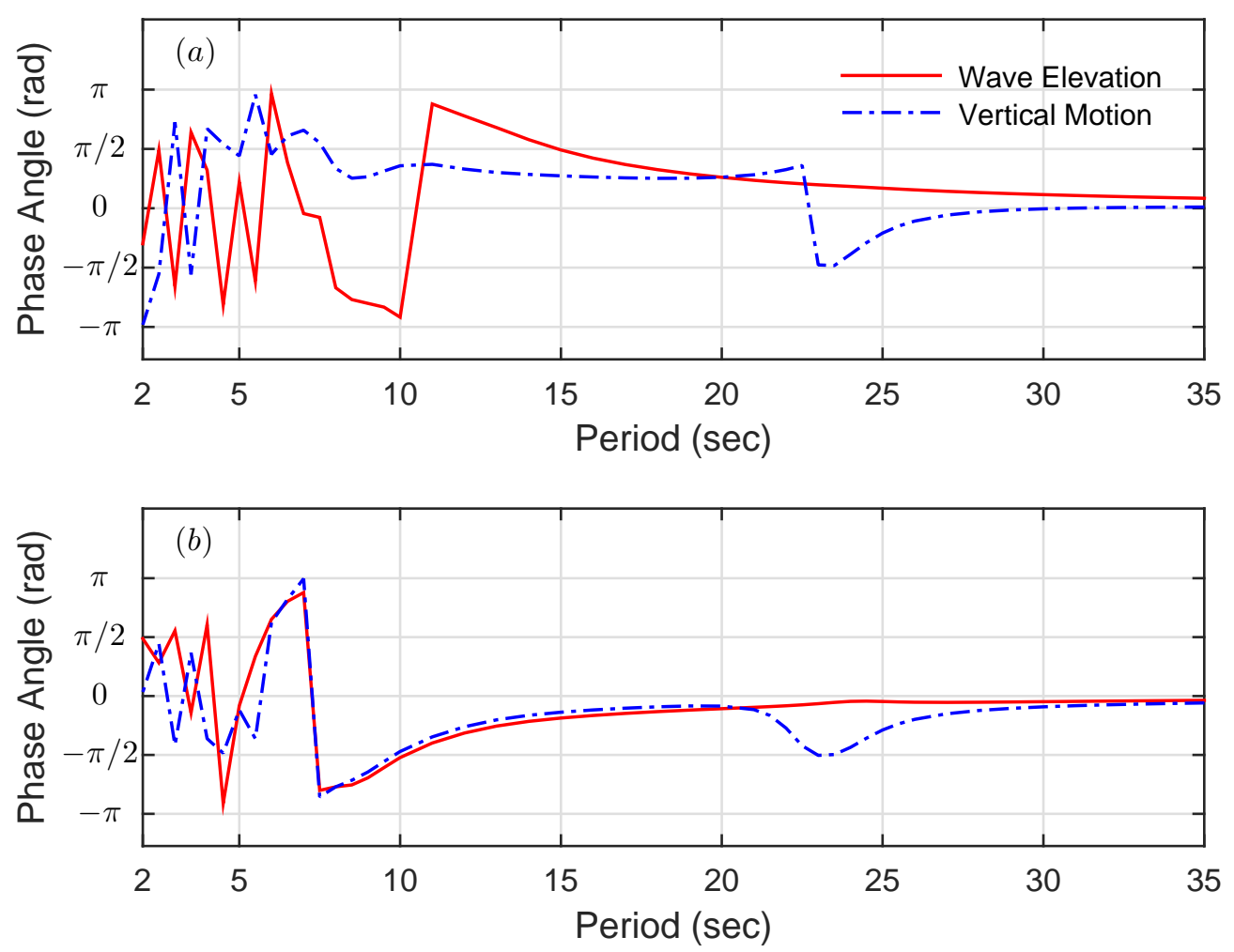

Figure 16: Phase angles of wave elevation and vertical motion in wave heading $\theta=45^{\circ}$. (a) AG45; (b) WP45.

wave heading $\theta=0^{\circ}$ is taken for analysis in the next section in this paper.

\section{Parametric Study}

Extensive parametric studies have been performed to examine the dependence of global performance on the main particulars of the floating production unit. The key dimensions include hull draft, column width, column spacing, column corner radius, pontoon height, pontoon width, and the size of cakepiece. Systematic numerical computations are performed and will be presented in the following subsections. In the course of parametric study, both the transverse and longitudinal GM are remained as 1.0 meter, which can be maintained in practice by adjusting the water ballast in pontoons and columns. The radiuses of gyration are assumed to be the same as those of base model because they can not be accurately estimated until the phase of detailed design. Both regular wave and irregular wave conditions are adopted for parametric studies. In regular wave condition, the motion response RAOs and total wave elevations at the worst airgap location AG0 are compared. In irregular wave condition, the statistics of the motion responses are compared in long-crested nonlinear waves (the wave amplification factor is 1.2). In addition, we also investigate the airgap for a peak wave period between 13 to 15 seconds, which is consistent with the typical $T_{p}$ range for a 100-year hurricane or typhoon condition in either GOM or North Sea.

\subsection{Effect of hull draft}

In order to examine the effects of hull draft, global motion analyses have been performed for a series of hull forms by varying the drafts. First, the case of regular waves is studied. The hull draft is increased from 

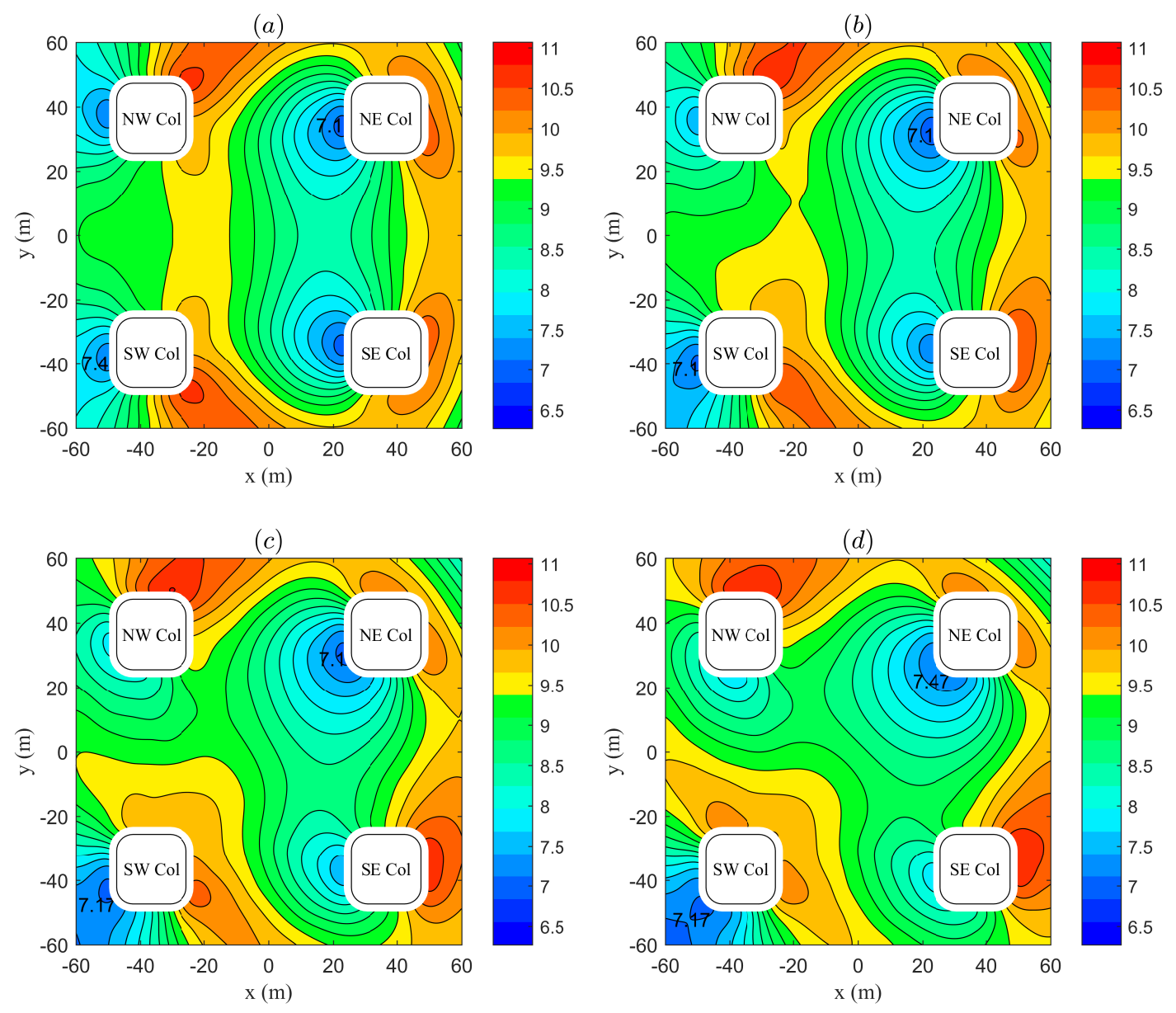

Figure 17: Contour of airgap in short-crested linear waves, $H_{s}=15.8 \mathrm{~m} ; T_{p}=15.4 \mathrm{sec}$; peak enhancement factor $\gamma=2.4$. (a) $\theta=0^{\circ}$; (b) $\theta=15^{\circ} ;$ (c) $\theta=30^{\circ}$; (d) $\theta=45^{\circ}$. 

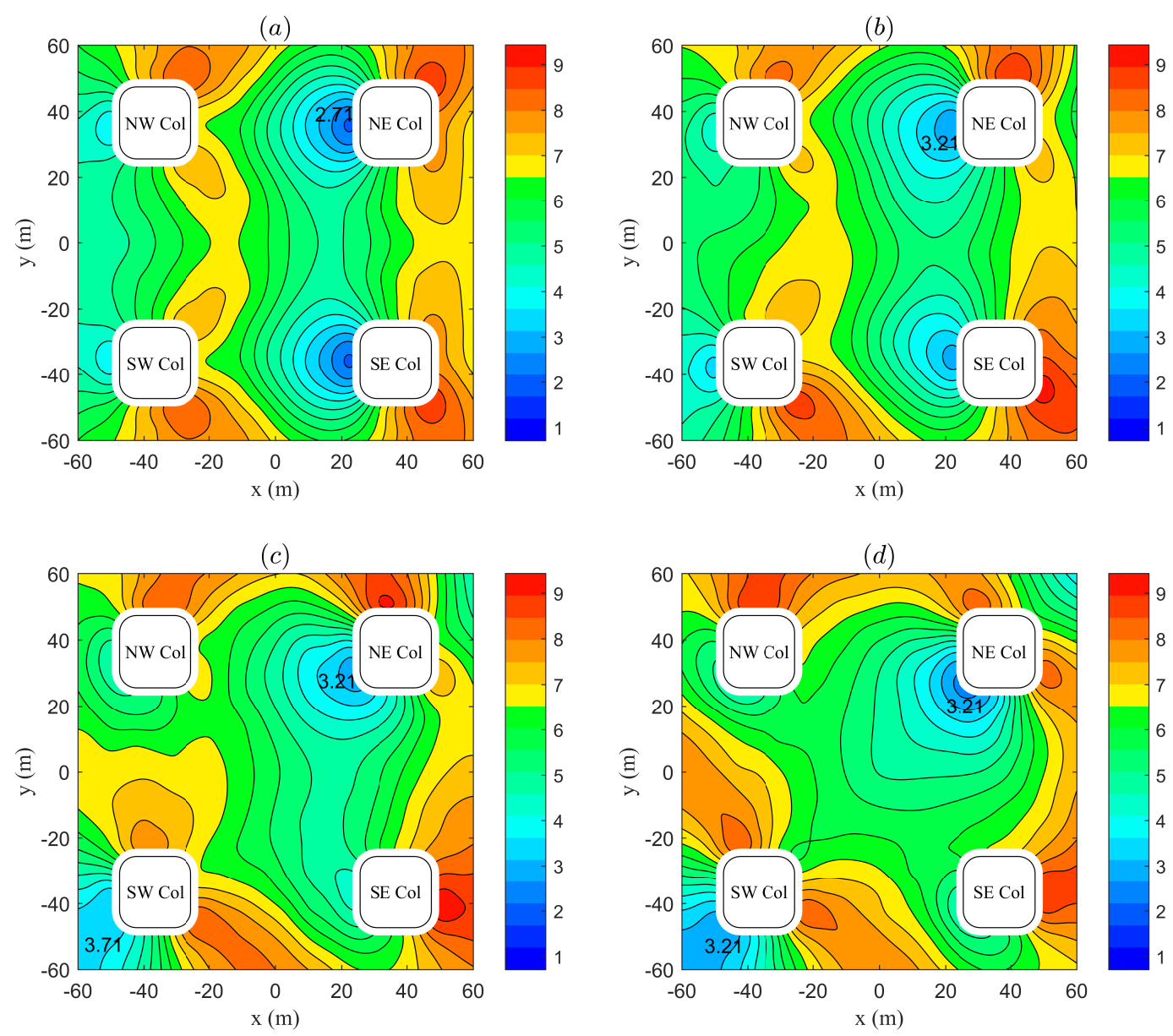

Figure 18: Contour of airgap in long-crested nonlinear waves, $H_{s}=15.8 \mathrm{~m} ; T_{p}=15.4$ sec; peak enhancement factor $\gamma=2.4$. (a) $\theta=0^{\circ}$; (b) $\theta=15^{\circ} ;$ (c) $\theta=30^{\circ} ;(\mathrm{d}) \theta=45^{\circ}$. 


\begin{tabular}{ccc} 
Table 4: Variations of hull draft \\
\hline Name & Unit & Draft \\
\hline draft1 & $\mathrm{m}$ & 26.0 \\
draft2 & $\mathrm{m}$ & 28.5 \\
draft3 & $\mathrm{m}$ & 31.0 \\
draft4 & $\mathrm{m}$ & 33.5 \\
\hline
\end{tabular}

26.0 to 33.5 meters as shown in Table 4, and the other hull parameters are the same as those listed in Table 1. The surge, heave and pitch motions are compared in Figure 19. The comparisons of wave elevation are also performed. As can be observed from the comparisons, the motion performance has been improved after increasing the hull draft. The surge hump around 7.5 seconds is suppressed from 0.28 to 0.23 when the draft increases to 33.5 meters. The heave hump around 17 seconds drops substantially from 0.62 to 0.49 , which is critical to the strength and fatigue of the riser system. The pitch motion hump around 7 seconds also decreases and the resonant motion around 11 seconds decreases from 0.78 to 0.53 . In short, the increase of hull draft has significant impact on the global motion responses in surge, heave and pitch. Figure 19(d) shows the wave elevations at the worst airgap location. As illustrated, by increasing draft, the maximum wave elevation is suppressed for wave periods between 8 and 12 seconds.

The phases of the motion responses are plotted in Figure 20, where the phase angles of heave, pitch and combined motions vary little with the increased draft. The heave motion is in phase with incident long wave and the pitch motion is out of phase with incident wave (phase angle about $\pi / 2$ ), which is expected. Figure 20(d) shows the comparisons of the phase angles of combined motion and wave elevation at the worst airgap location AG0. As illustrated, for wave periods from 10 to 20 seconds, the combined vertical motion is almost in phase of the wave elevation. It should be noted that the peak wave period in extreme wave condition, i.e. 100year hurricane condition, is typically around 14 to 15 seconds, which indicates that wave elevation in extreme irregular waves is in phase with the combined motion at AG0.

In addition, the case of irregular waves is investigated through numerical computations. The comparisons of root mean square (RMS) of surge, heave and pitch responses are presented in Figure 21. The MPM airgap at the location AG0 in wave heading $\theta=0^{\circ}$ is also presented. As illustrated in the plots, by increasing the draft, root mean square (RMS) of surge motion response decreases when $T_{p}$ goes beyond 7 seconds. The heave motion response RMS reduces as draft increases for peak wave period ranging from 10 to 20 seconds (around 17 seconds). Figure 21(d) suggests that when peak wave period is below 14 seconds, the reduction of wave elevation due to increased draft is dominant, so that the airgap is increased. However, as peak wave period is beyond 14 seconds, the reduction of heave motion is dominant so that the airgap reduces.

\subsection{Effect of column width}

The effects of column width (CW) on motion responses, wave elevations and airgap are investigated in the present subsection. The set of selected column widths is listed in Table 5. Figure 22 presents the comparisons of the motion response RAOs and wave elevations in regular waves. As illustrated, the heave resonant period drops as $\mathrm{CW}$ increases, due to increased hydrostatic restoring coefficient. The resonant pitch motion amplitude 

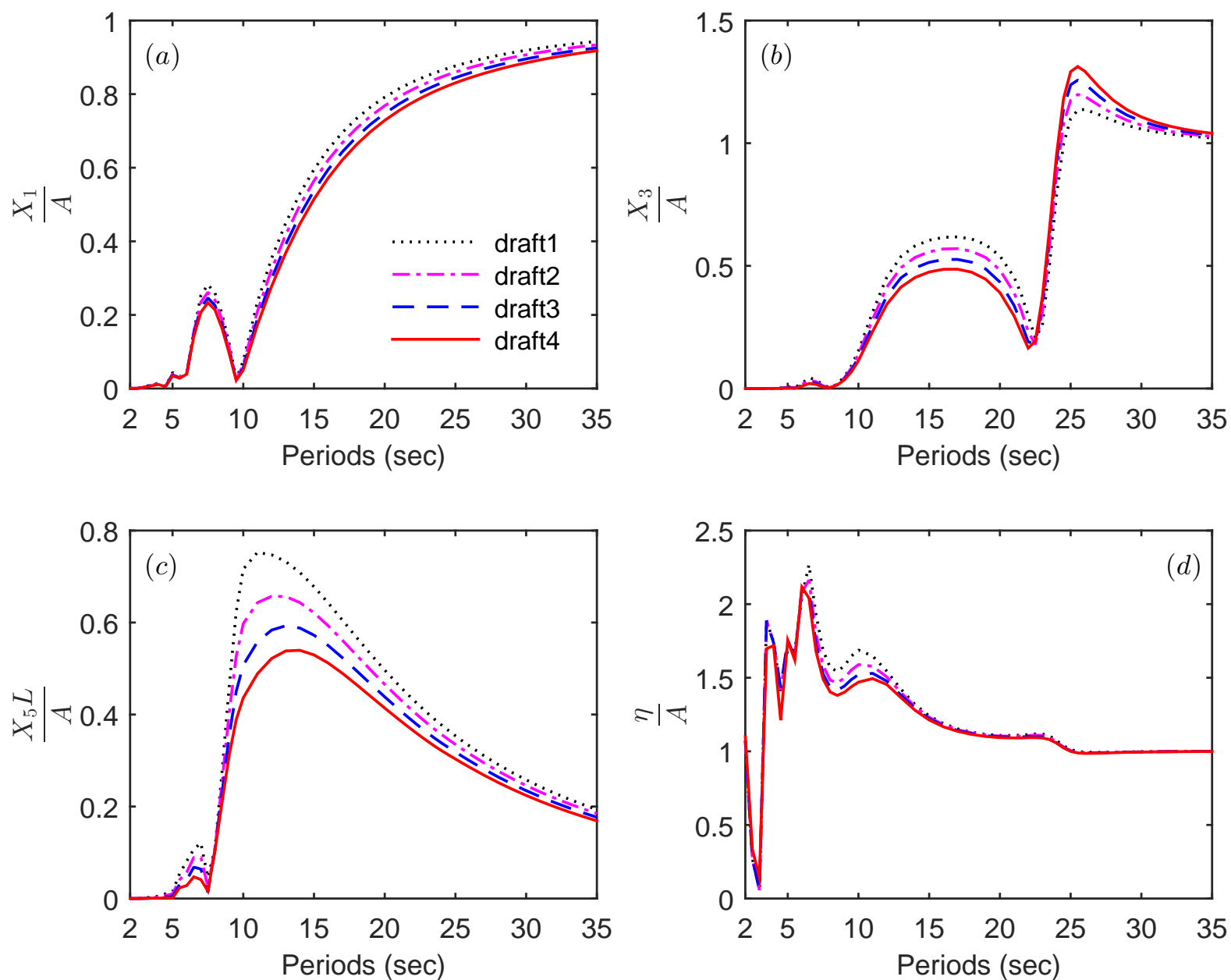

Figure 19: Effect of hull draft on motion responses and wave elevations in regular waves: (a) Surge RAO; (b) Heave RAO; (c) Pitch RAO; (d) Wave elevation at AG0. 

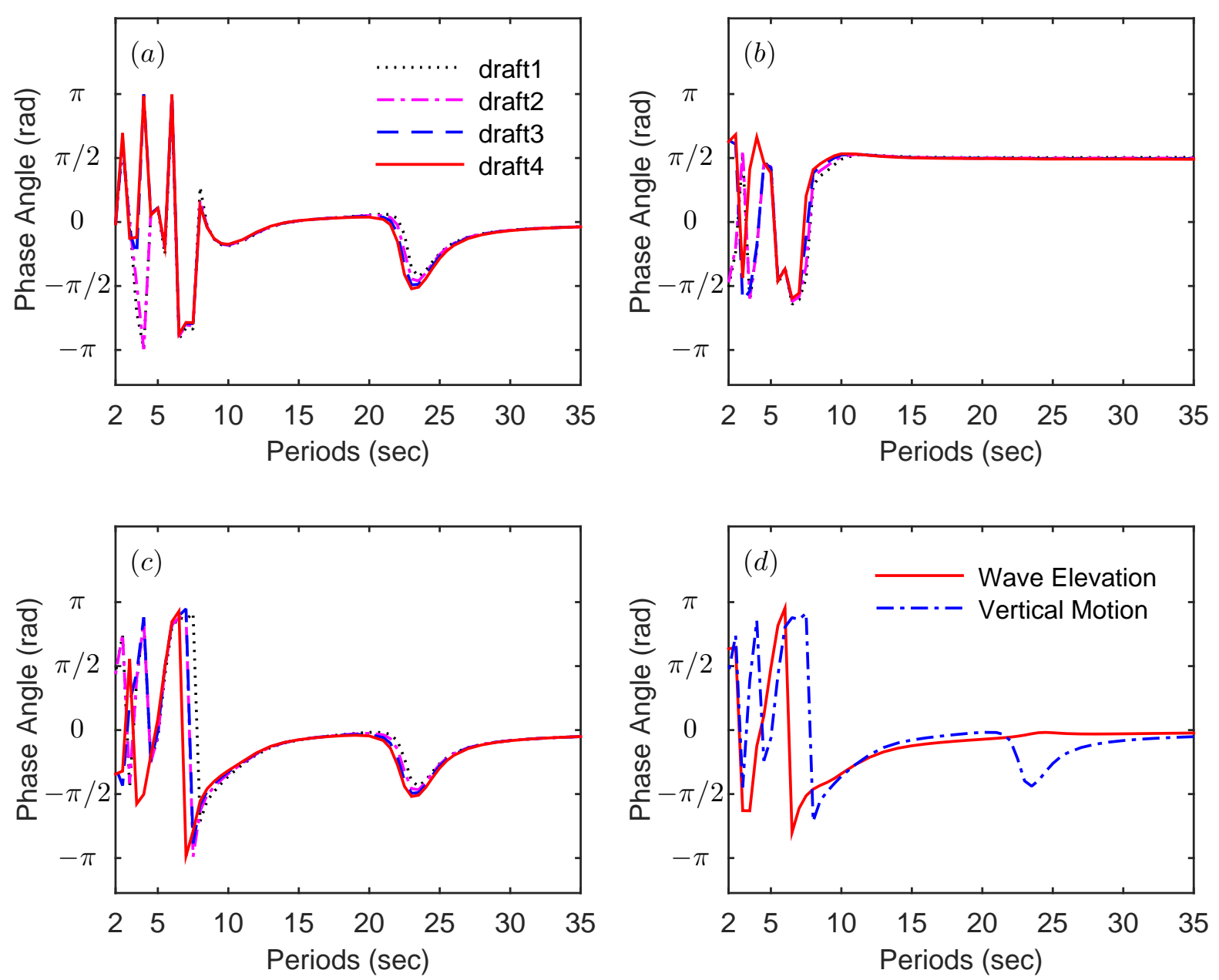

Figure 20: Phase angles of the motion and wave elevation: (a) Heave RAO; (b) Pitch RAO; (c) Vertical motion RAO at AG0; (d)

Wave elevation and vertical motion at AG0 of draft1. 

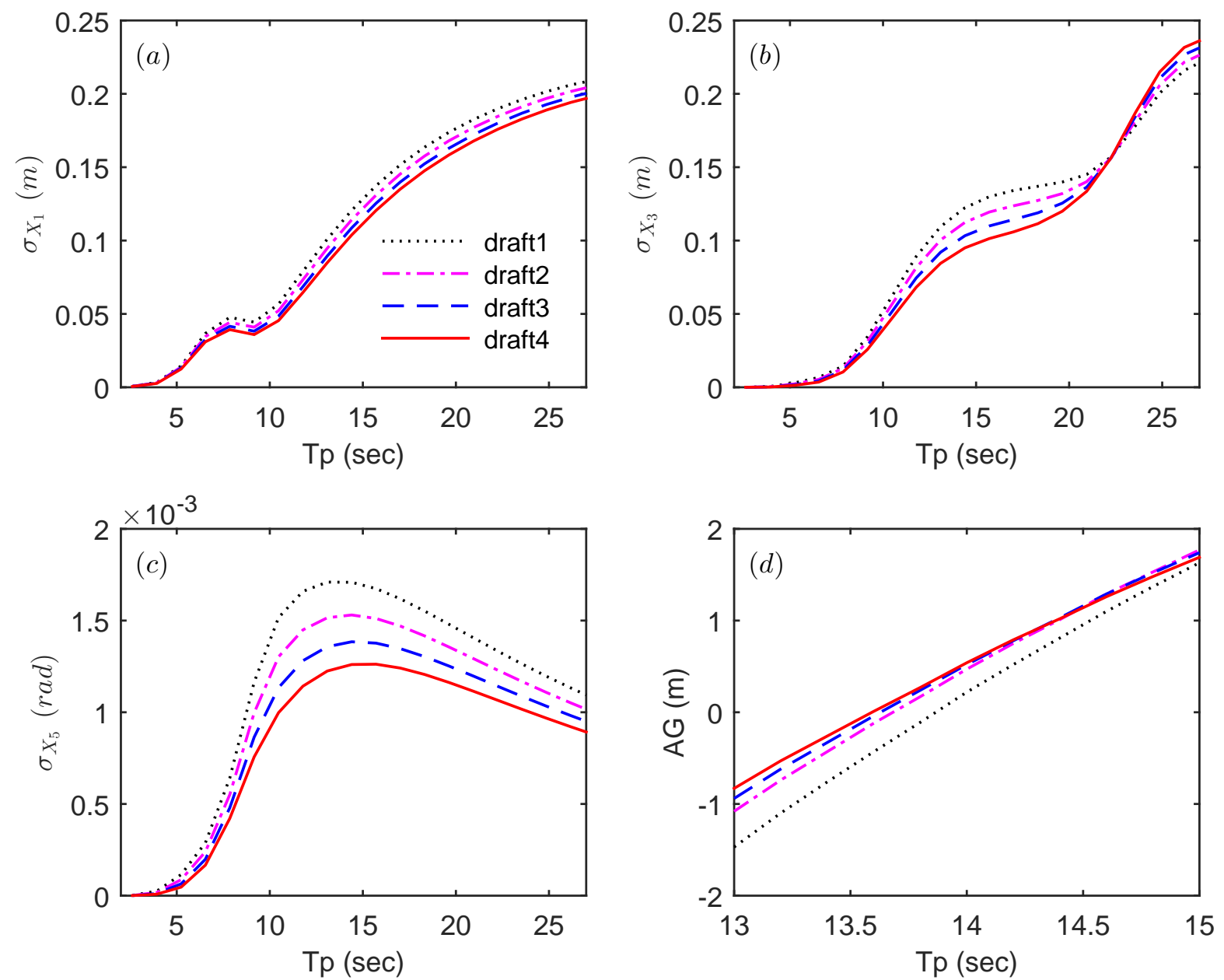

Figure 21: Effect of hull draft on motion responses and airgap in irregular waves: (a) RMS of surge motion; (b) RMS of heave motion; (c) RMS of pitch motion; (d) Airgap. Parameters of irregular waves: $H_{s}=15.8 \mathrm{~m}, \gamma=2.4$. 


\begin{tabular}{lcc}
\multicolumn{3}{c}{ Table 5: } \\
Name & Uniations of column width & Column Width \\
\hline cw1 & $\mathrm{m}$ & 19.20 \\
cw2 & $\mathrm{m}$ & 20.48 \\
cw3 & $\mathrm{m}$ & 21.76 \\
$\mathrm{cw} 4$ & $\mathrm{~m}$ & 23.04 \\
\hline
\end{tabular}

\begin{tabular}{|c|c|c|}
\hline Name & Unit & Column Spacing \\
\hline $\operatorname{cs} 1$ & $\mathrm{~m}$ & 64.96 \\
\hline $\operatorname{cs} 2$ & $\mathrm{~m}$ & 68.96 \\
\hline $\operatorname{cs} 3$ & $\mathrm{~m}$ & 72.96 \\
\hline $\operatorname{cs} 4$ & $\mathrm{~m}$ & 76.96 \\
\hline
\end{tabular}

also decreases. As shown in Figure 22(d), the wave elevation at the worst airgap point AG0 increases as the relative column corner radius (scaled by $\mathrm{CW}$ ) reduces.

Figure 23 illustrates the comparisons of the motion responses and airgap in irregular waves. As can be observed, the heave motion response for $T_{p}$ around 14 seconds is slightly affected by the column width. In addition, Figure 23(c) reveals that the pitch motion can be suppressed by increasing CW. Besides, increasing CW can lead airgap to be reduced. This is because that larger CW causes relatively higher wave elevation while small effects on combined vertical motion.

\subsection{Effect of column spacing}

In order to find out the effects of column spacing (CS), a series of numerical tests have been performed by varying the column spacing, which are summarized in Table 6 . As CS varies, the total length and beam of the FPU are changed. This causes the total displacement and added mass of the floater to vary so that the hydrodynamic behavior of the FPU is modified. The comparisons of the motion responses are presented in Figure 24. As can be seen, the cancellation periods for both surge and heave motions will go up when CS increases. At the same time, both the surge and heave humps increase with the growth of CS. As expected, heave resonant period grows with increasing column spacing. In addition, the pitch resonant motion around 13 seconds will increase when CS goes up. Figure 24(d) presents the comparison of wave elevation for different CS. It indicates that the wave elevation is not sensitive to column spacing.

Figure 25 illustrates the effects of column spacing on motion responses and airgap in irregular waves. The comparison indicates that the surge motion for peak wave period from 7 to 9 seconds increases as column spacing increases. However, the surge motion RMS decreases for peak wave period $T_{p}$ larger than 11 seconds. Figure 25(b) suggests that smaller column spacing CS can achieve better heave motion performance for peak wave period between 14 to 18 seconds. In addition, as illustrated in Figure 25(c), the pitch motion can be improved by reducing CS. In addition, the airgap for $T_{p}$ between 13 and 15 seconds gets worse by reducing the CS. 

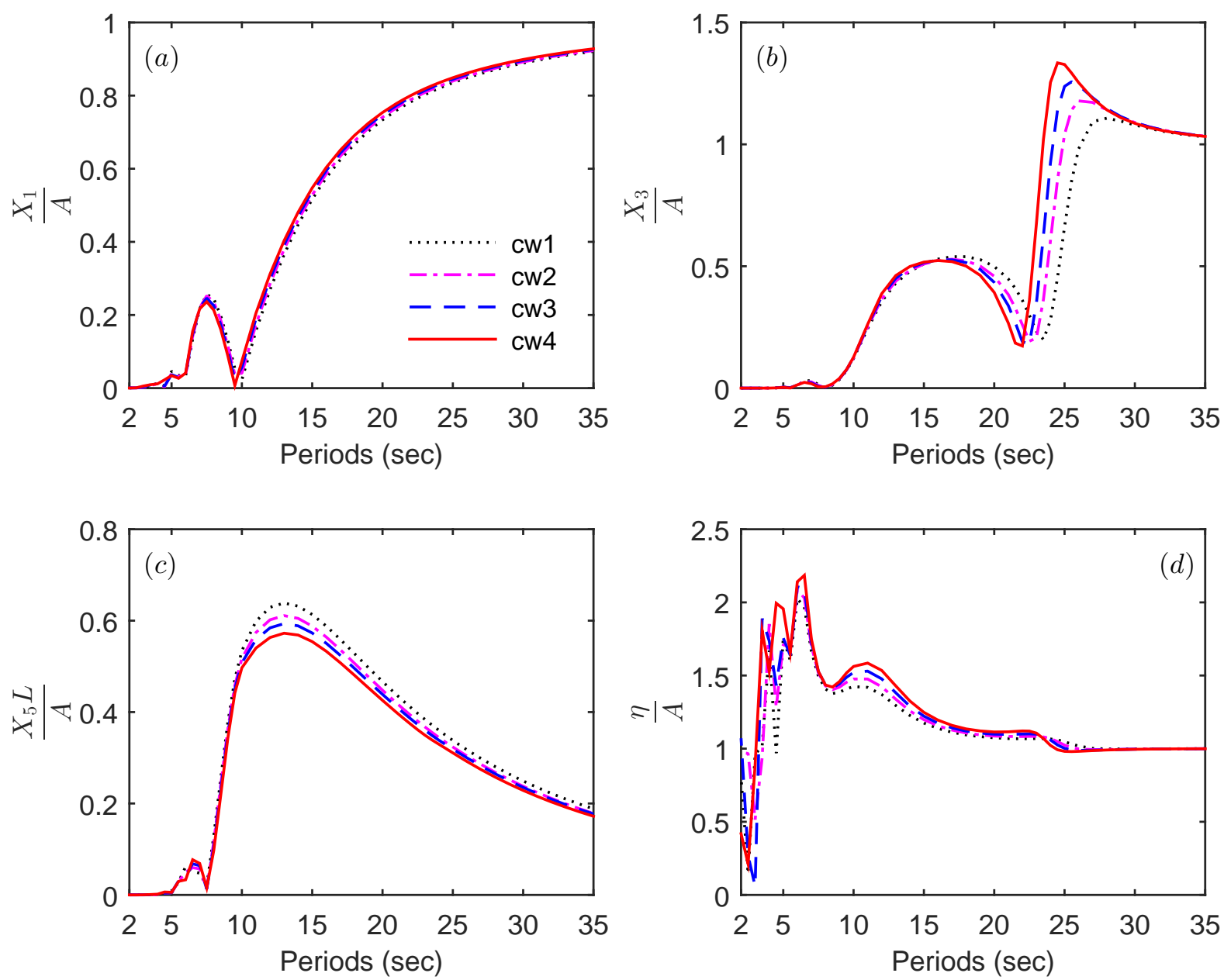

Figure 22: Effect of column width (CW) in regular waves: (a) Surge RAO; (b) Heave RAO; (c) Pitch RAO; (d) Wave elevation. 

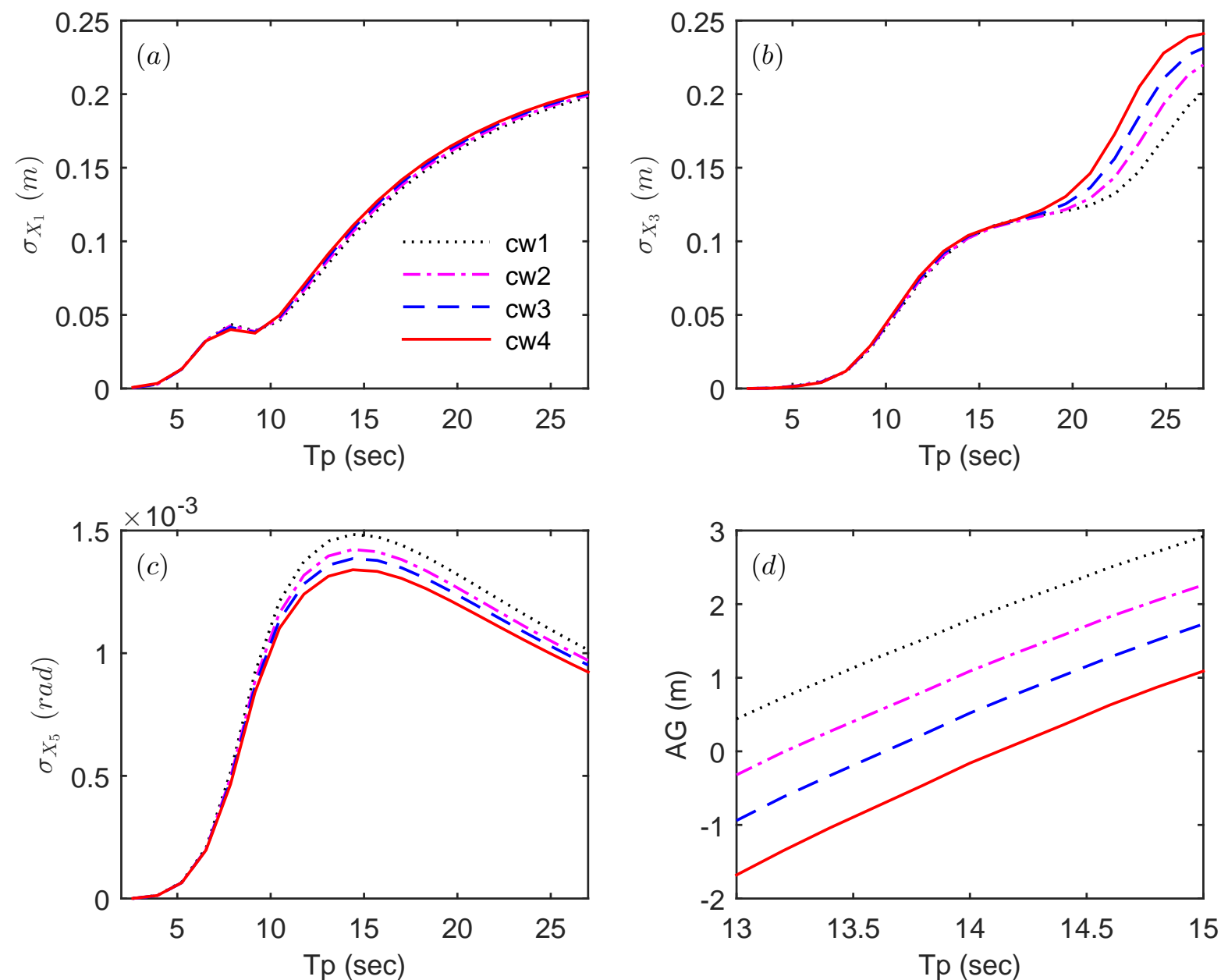

Figure 23: Effect of column width (CW) in irregular waves: (a) RMS of surge motion; (b) RMS of heave motion; (c) RMS of pitch motion; (d) Airgap. Parameters of irregular waves: $H_{s}=15.8 \mathrm{~m}, \gamma=2.4$. 

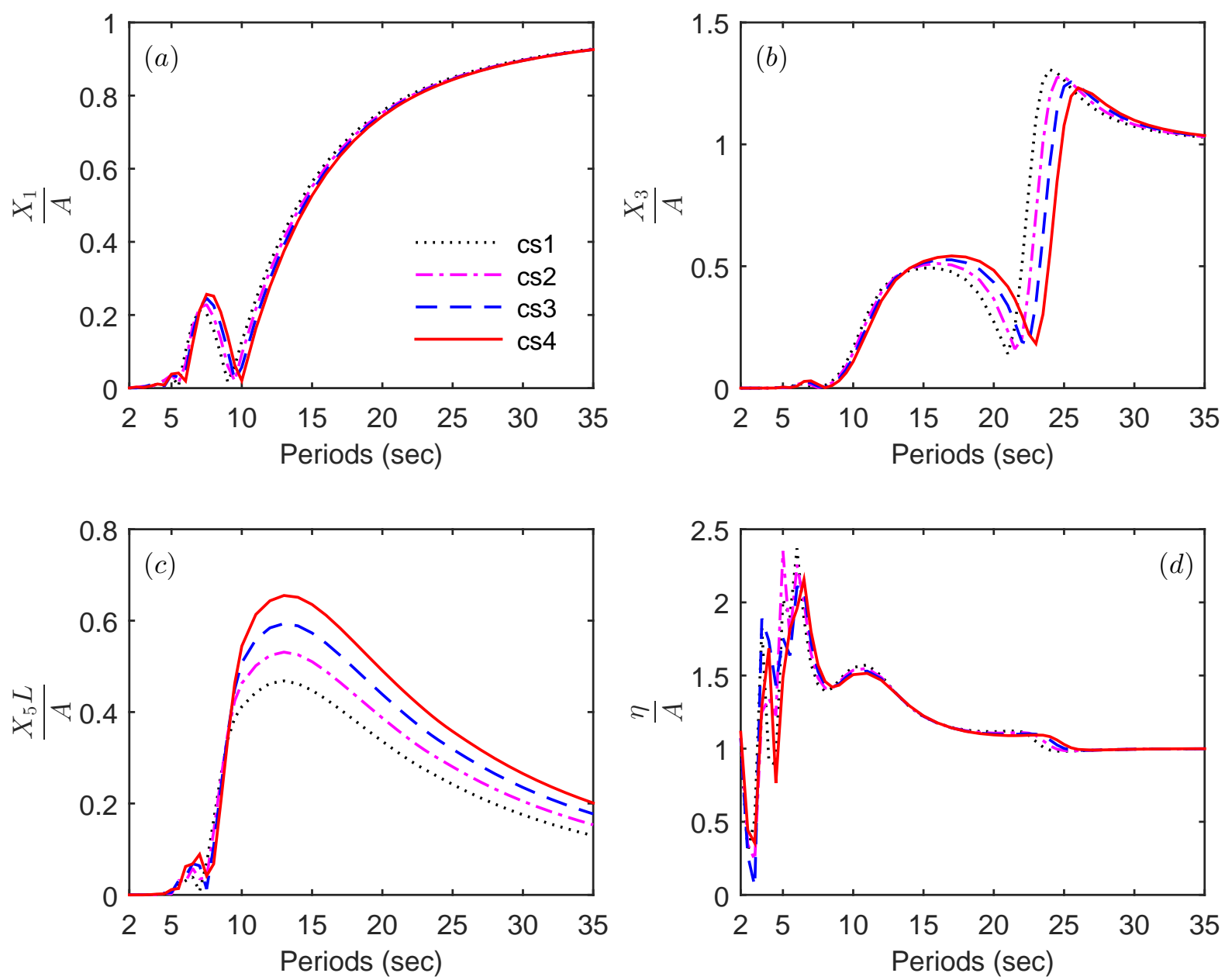

Figure 24: Effect of column spacing (CS) in regular waves: (a) Surge RAO; (b) Heave RAO; (c) Pitch RAO; (d) Wave elevation. 

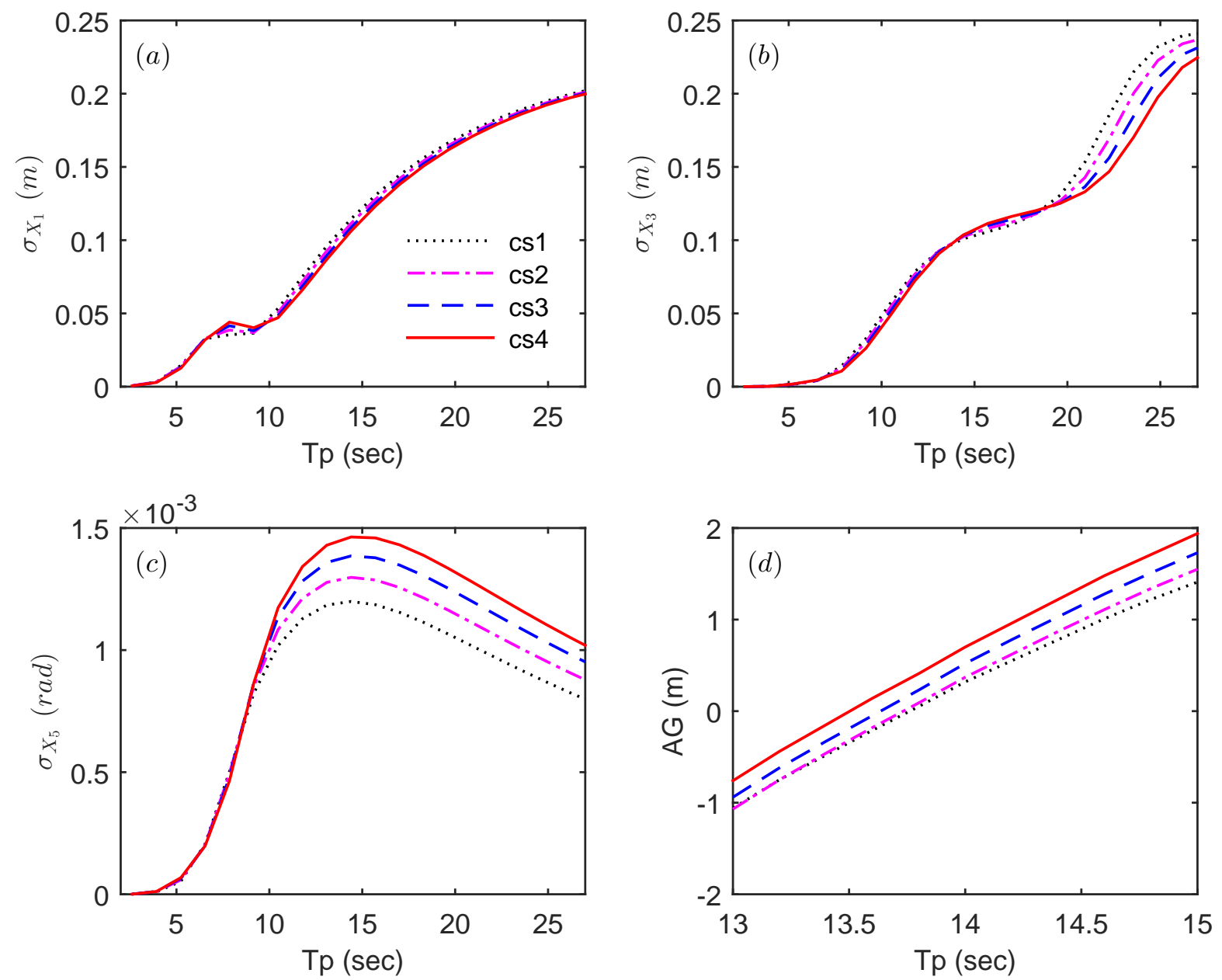

Figure 25: Effect of column spacing (CS) in irregular waves: (a) RMS of surge motion; (b) RMS of heave motion; (c) RMS of pitch motion; (d) Airgap. Parameters of irregular waves: $H_{s}=15.8 \mathrm{~m}, \gamma=2.4$. 


\begin{tabular}{|c|c|c|}
\hline Name & Unit & Column Corner Radius \\
\hline $\operatorname{ccr} 1$ & $\mathrm{~m}$ & 3.045 \\
\hline $\operatorname{ccr} 2$ & $\mathrm{~m}$ & 5.045 \\
\hline ccr3 & $\mathrm{m}$ & 7.045 \\
\hline $\operatorname{ccr} 4$ & $\mathrm{~m}$ & 9.045 \\
\hline
\end{tabular}

\begin{tabular}{|c|c|c|}
\hline Name & Unit & Pontoon Height \\
\hline ph1 & $\mathrm{m}$ & 6.88 \\
\hline ph2 & $\mathrm{m}$ & 8.88 \\
\hline ph3 & $\mathrm{m}$ & 10.88 \\
\hline ph4 & $\mathrm{m}$ & 12.88 \\
\hline
\end{tabular}

\subsection{Effect of column corner radius}

Typically, the cross-section of the columns for a SEMI is a square with four rounded corners. However, the effect of the column corner radius (CCR) on the hydrodynamic performance has not been well understood. Therefore, a parametric study is performed to examine this effect. The main particulars are fixed except for the column corner radius. The variations of CCR are listed in Table 7. Figure 26 shows the comparison for regular waves. As can be seen, the surge motion does not depend on the CCR. Nevertheless, both the cancellation period and resonant period of heave motion increase with the increasing CCR. With the growth of CCR, the resonant pitch motion increases by a small amount. In addition, the wave elevation around the column decreases as CCR increases.

Figure 27 presents the comparisons of motion responses and MPM airgap in irregular waves. Consistent with the solutions in regular waves, the surge motion in irregular waves is not sensitive to CCR. As CCR increases, the heave motion gets a little worse for peak wave period $T_{p}$ between 14 to 19 seconds. As peak wave period $T_{p}$ goes beyond 20 seconds, the heave motion decreases with the increase of CCR. For peak wave period between 13 and 15 seconds, larger CCR results in better airgap. It is because that larger CCR will cause larger vertical motion and smaller wave elevation.

\subsection{Effect of pontoon height}

The main contribution to wave exciting force in heave comes from the pontoons. Thus, the optimization of pontoon is critical. In this subsection, the height of pontoon is varied and the other main hull parameters remain the same. We tested four different pontoon heights, which are listed in Table 8. By rigorous comparisons for case of regular waves, as shown in Figure 28, it is shown that the heave cancellation period can be significantly affected by the pontoon height. As pontoon height increases, the cancellation period goes up. As shown in Figure 28(d), the wave elevation is amplified as the pontoon height increases. It is because wave amplification effects are intensified when the top of pontoon approaches to calm water plane. 

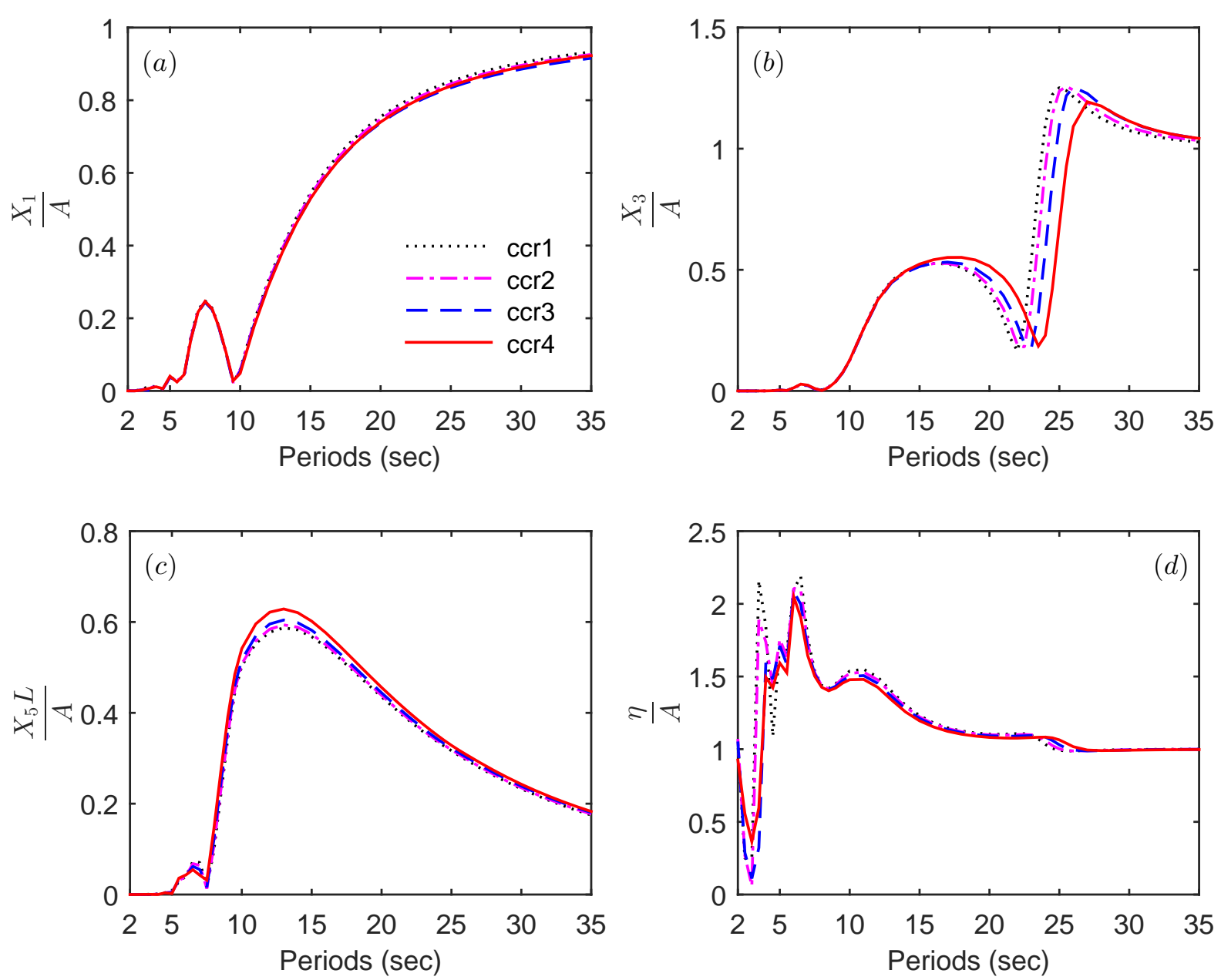

Figure 26: Effect of column corner radius (CCR) in regular waves: (a) Surge RAO; (b) Heave RAO; (c) Pitch RAO; (d) Wave elevation. 

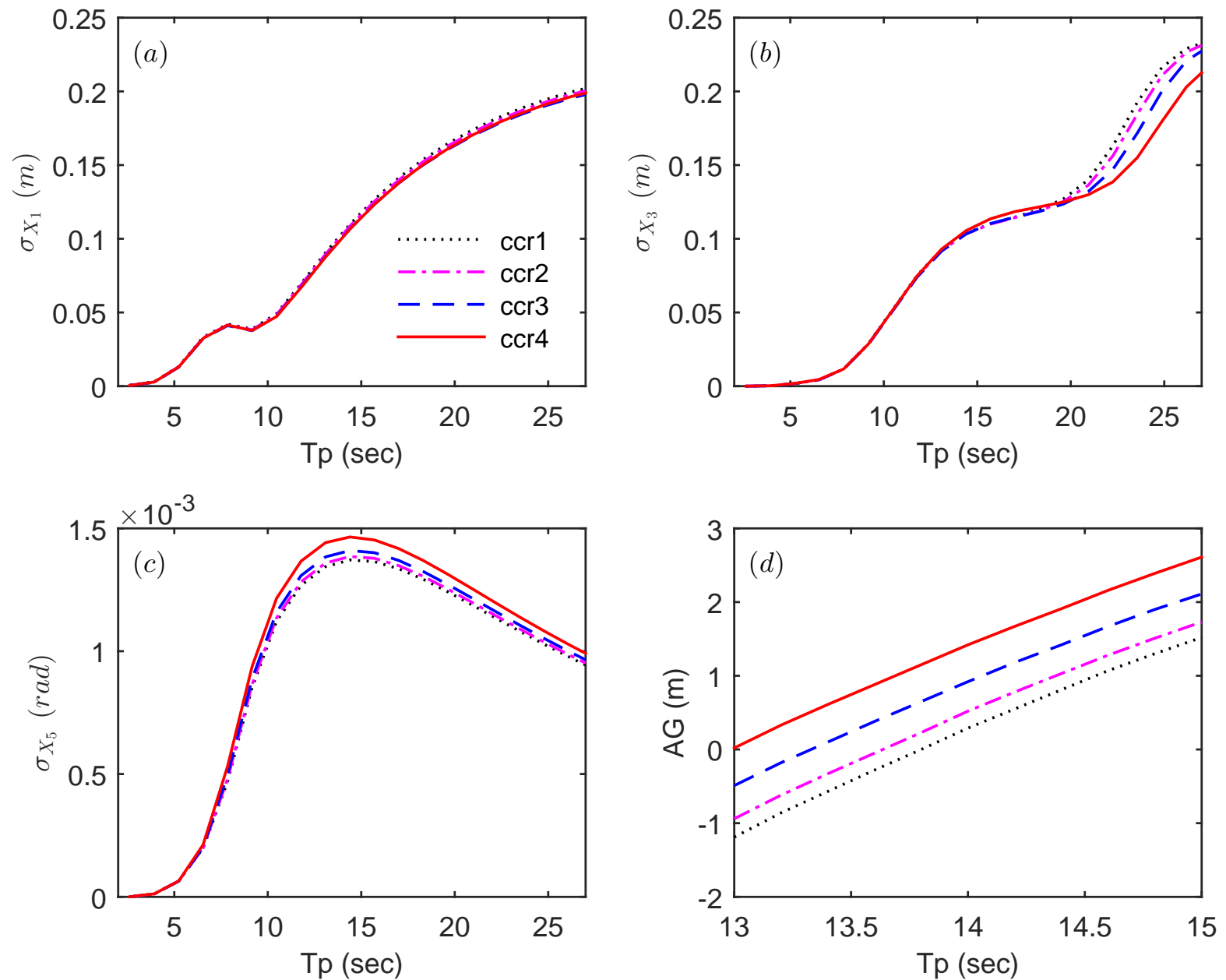

Figure 27: Effect of column corner radius (CCR) in irregular waves: (a) RMS of surge motion; (b) RMS of heave motion; (c) RMS of pitch motion; (d) Airgap. Parameters of irregular waves: $H_{s}=15.8 \mathrm{~m}, \gamma=2.4$. 

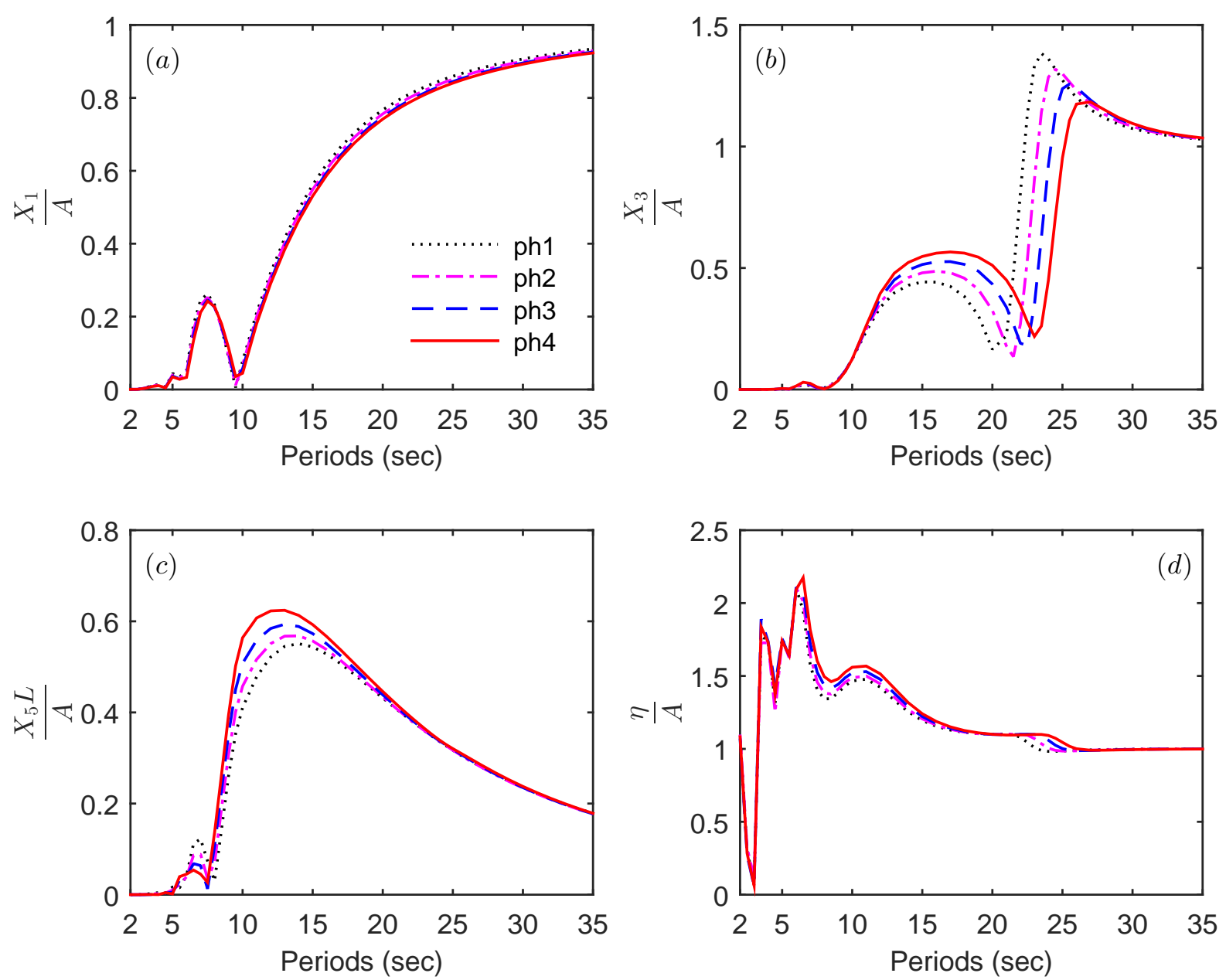

Figure 28: Effect of pontoon height $(\mathrm{PH})$ in regular waves: (a) Surge RAO; (b) Heave RAO; (c) Pitch RAO; (d) Wave elevation.

Figure 29 presents the comparisons for irregular waves. As illustrated, the pontoon height has almost no impact on the surge motion response. However, the increase of $\mathrm{PH}$ can make the heave motion to be worse for $T_{p}$ around 15 seconds. Therefore, with the growth of $\mathrm{PH}$, the airgap gets worse as $\mathrm{PH}$ affects wave elevation much more than the heave motion.

\subsection{Effect of pontoon width}

The pontoon width is a key hull parameter which may impact the motion performance. In order to examine this effect, we change the width of pontoon by only adjusting the outer side of pontoon. The purpose for this design is to reduce the heave motion at the riser porch, which is usually placed at the inner side of pontoon. Different pontoon widths are summarized in Table 9 .

Figure 30 presents the computational results for regular waves. As shown, variation of PW does not affect surge motion RAO. However, the heave motion RAO is significantly impacted by the PW. As PW increases, both the heave cancellation period and resonant period increase. The amplitude of heave hump increases correspondingly. The pitch resonant amplitude around 14 seconds also goes up as PW increases. As can be observed from Figure 30(d), pontoon width has trivial effect on the wave elevation.

Figure 31 presents the comparisons for irregular waves. As illustrated, the heave motion RMS is affected 

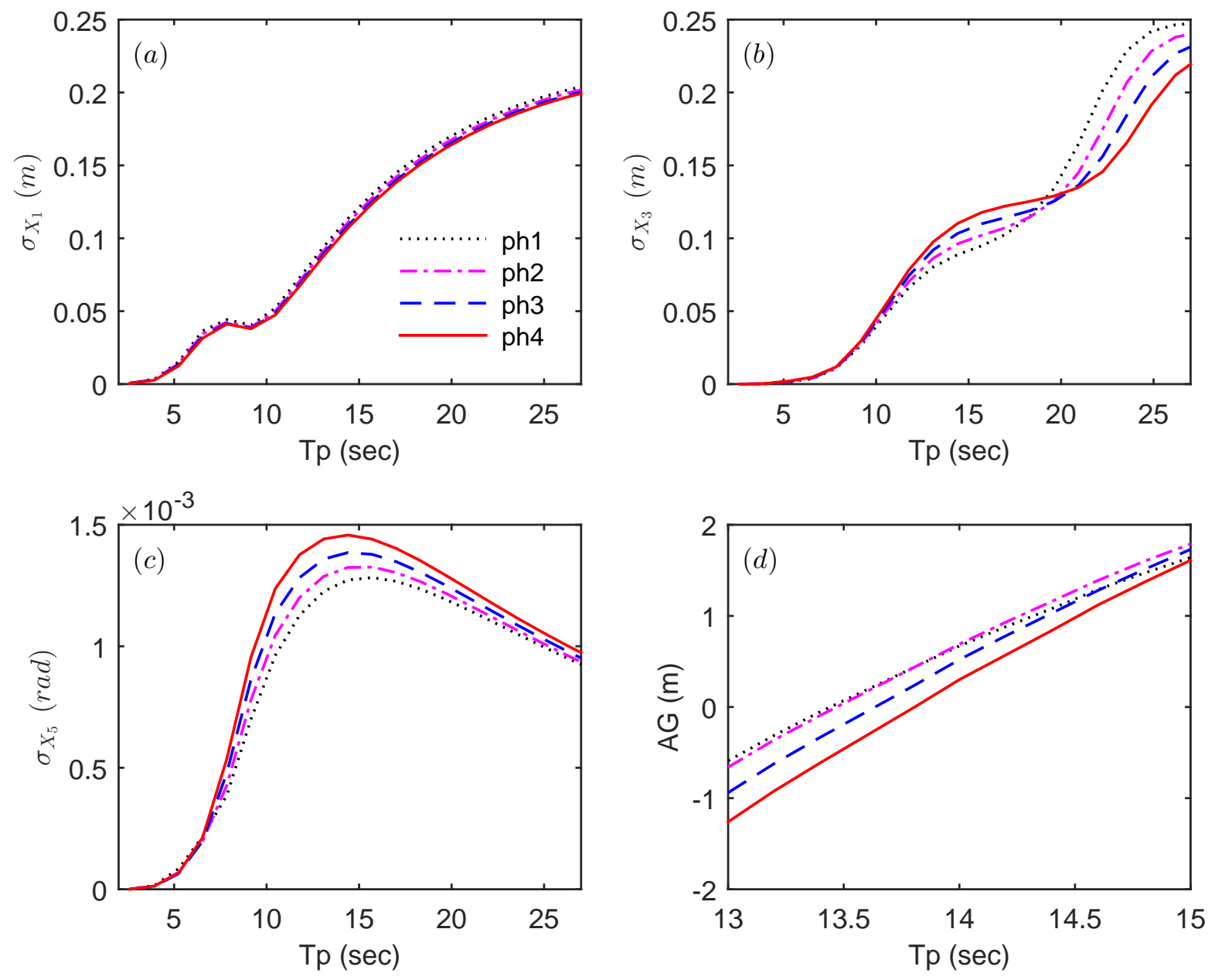

Figure 29: Effect of pontoon height (PH) in irregular waves: (a) RMS of surge motion; (b) RMS of heave motion; (c) RMS of pitch motion; (d) Airgap. Parameters of irregular waves: $H_{s}=15.8 \mathrm{~m}, \gamma=2.4$.

Table 9: Variations of of pontoon width

\begin{tabular}{lcc}
\hline Name & Unit & Pontoon Width \\
\hline pw1 & $\mathrm{m}$ & 12.76 \\
pw2 & $\mathrm{m}$ & 15.76 \\
pw3 & $\mathrm{m}$ & 18.76 \\
pw4 & $\mathrm{m}$ & 21.76 \\
\hline
\end{tabular}



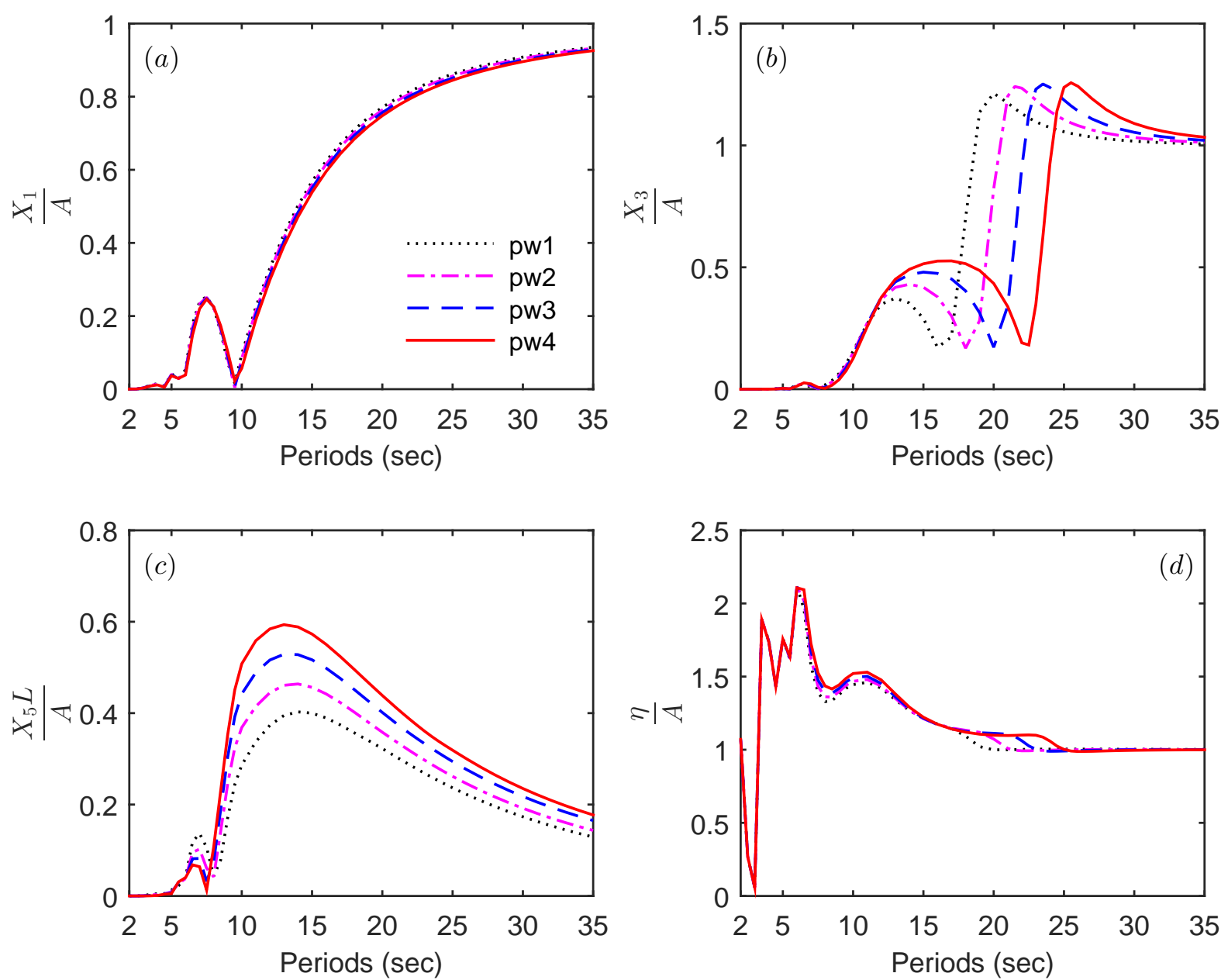

Figure 30: Effect of pontoon width (PW) in regular waves: (a) Surge RAO; (b) Heave RAO; (c) Pitch RAO; (d) Wave elevation.

significantly by PW. As PW increases from 12.76 to 21.76 meters, the heave motion increases for a $T_{p}$ between 11 and 14 seconds, and the airgap goes up for $T_{p}$ between 13 and 15 seconds.

\subsection{Effect of cakepiece}

The cakepiece $(\mathrm{CP})$ is a key structural component which is placed at the intersection between the pontoon and the column for enhancing the integrity of the whole floater. The effects of cakepiece on motion responses in regular waves are presented in Figure 32, where different sizes of the cakepiece are summarized in Table 10. As shown in the figure, the cakepiece has trivial effects on surge motion. However, both heave cancellation and resonant periods are affected by the size of cakepiece. As the size of cakepiece increases, the mass and added

Table 10: Variations of the width of cakepiece

\begin{tabular}{ccc}
\hline Name & Unit & cakepiece \\
\hline cp1 & $\mathrm{m}$ & 5.12 \\
$\mathrm{cp} 2$ & $\mathrm{~m}$ & 8.12 \\
$\mathrm{cp} 3$ & $\mathrm{~m}$ & 11.12 \\
$\mathrm{cp} 4$ & $\mathrm{~m}$ & 14.12 \\
\hline
\end{tabular}



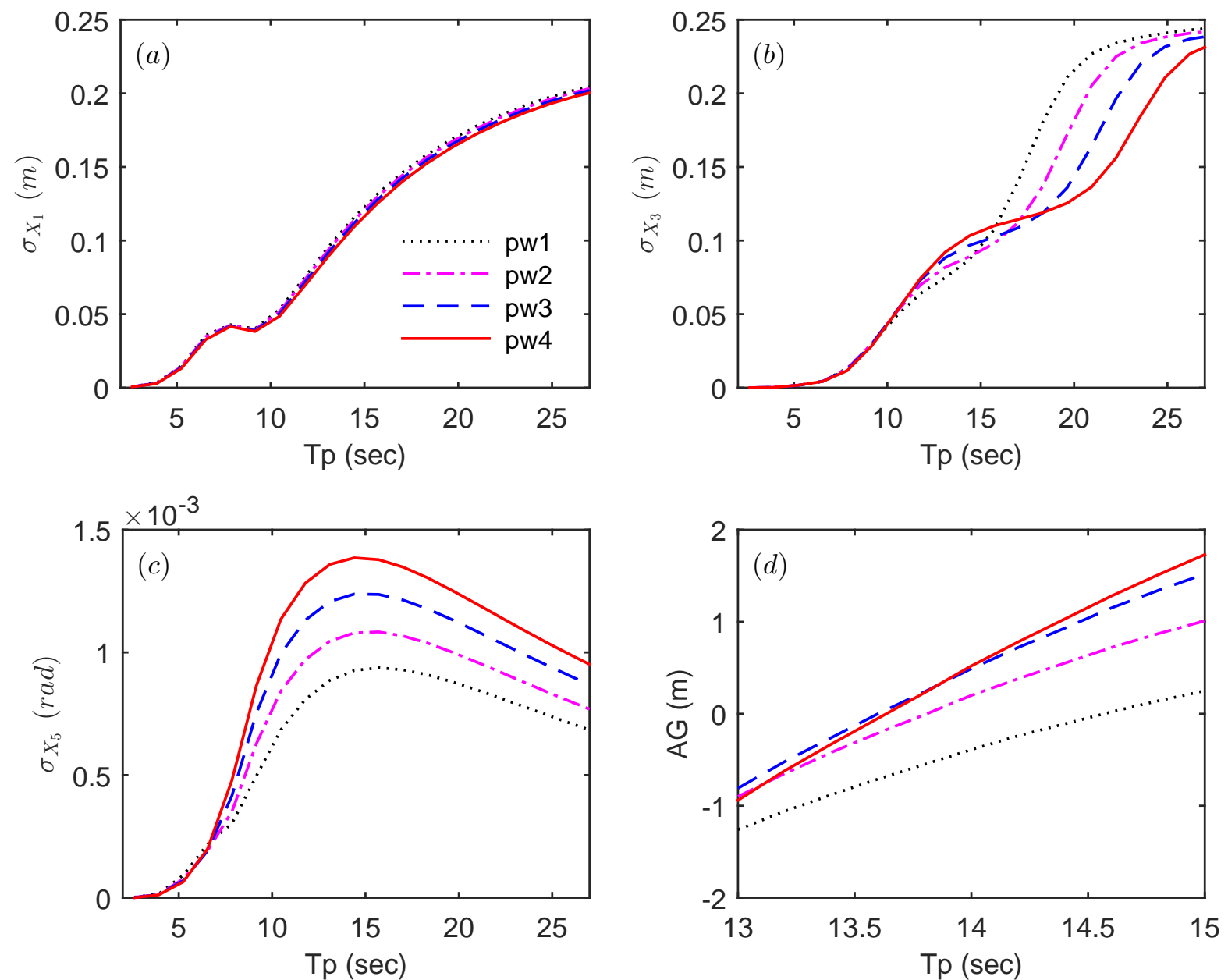

Figure 31: Effect of pontoon width (PW) in irregular waves: (a) RMS of surge motion; (b) RMS of heave motion; (c) RMS of pitch motion; (d) Airgap. Parameters of irregular waves: $H_{s}=15.8 \mathrm{~m}, \gamma=2.4$. 

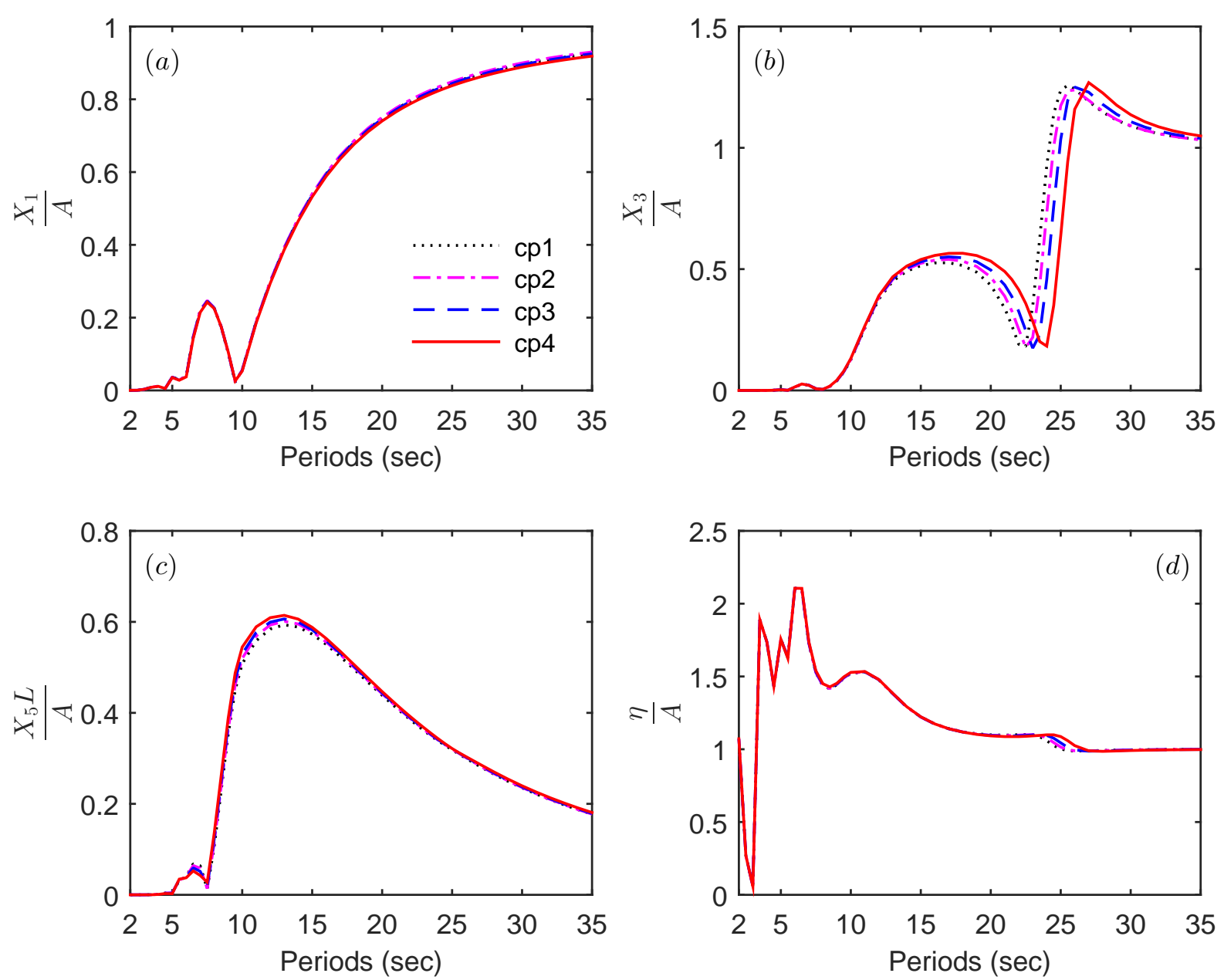

Figure 32: Effect of width of cakepiece (CP) in regular waves: (a) Surge RAO; (b) Heave RAO; (c) Pitch RAO; (d) Wave elevation.

mass increase, which further causes the heave resonant period and hump amplitude to increase. In addition, the pitch motion and wave elevation does not change with $\mathrm{CP}$ appreciably.

Figure 33 presents the numerical results for irregular waves. The comparisons indicate that the surge motion responses are almost the same for different CP. As CP increases, the heave response also increases for $T_{p}$ less than 20 seconds, but decreases for $T_{p}$ longer than 20 seconds which usually stands for a swell. Because of that, larger $\mathrm{CP}$ will lead to higher heave motion and a more positive airgap, as presented in Figure 32(d).

\section{Conclusions}

We investigate the strategies for optimizing a semi-submersible FPU in order to improve its global hydrodynamic performance, including motion responses in regular and irregular waves, second-order mean drift forces, wave elevations inside moonpool and airgap. We first study the hydrodynamic behavior of a typical SEMI FPU. By examining numerical results, it is revealed that the motions are mostly smaller in short-crested waves than those in long-crested waves for the distribution of wave energy. The maximum wave elevation occurs in $45^{\circ}$ wave heading near the Northeast (NE) column. This can be attributed to the fact that wave diffraction is intensified when it is close to the wall. This worst wave elevation point is denoted as WP45. The minimum 

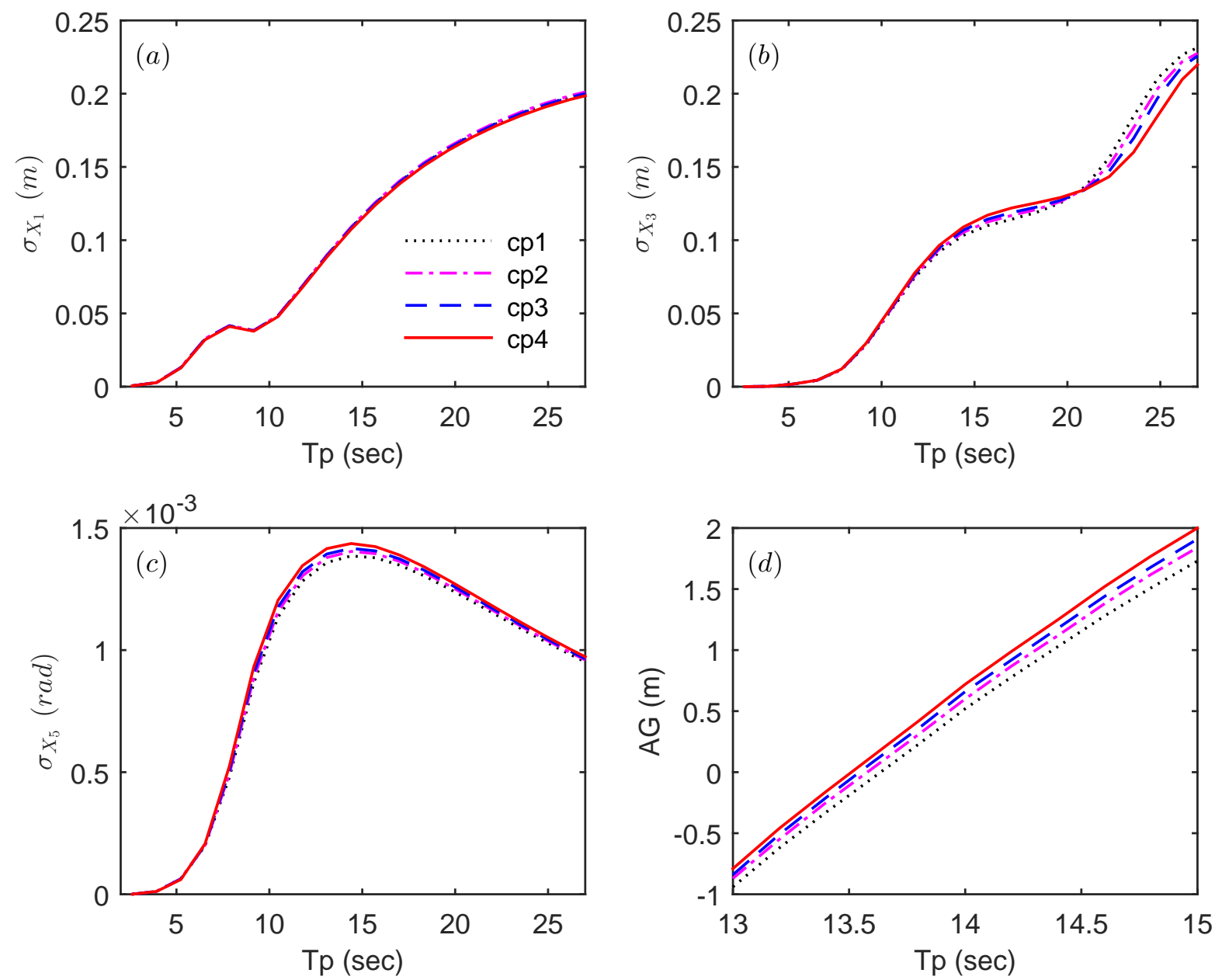

Figure 33: Effect of width of cakepiece (CP) in irregular waves; (a) RMS of surge motion; (b) RMS of heave motion; (c) RMS of pitch motion; (d) Airgap. Parameters of irregular waves: $H_{s}=12.3 \mathrm{~m}, \gamma=2.4$. 
airgap occurs in $45^{\circ}$ wave heading at AG45 near the Southwest (SW) column in long-crested linear waves. This is because that the effect of vertical motion at AG45 is smaller than that at WP45 on sustaining airgap due to the phase difference between wave elevation and vertical motion. The airgap in short-crested waves is much smaller than that in long-crested waves. The worst airgap points in long-crested nonlinear waves are located at the left side of $\mathrm{NE}$ and $\mathrm{SE}$ columns in $0^{\circ}$ wave heading, since the effect of wave elevation is stronger than that of vertical motion on airgap. The point next to NE column is denoted as AG0.

Comprehensive parametric studies have been carried out in order to identify the main particulars which can affect the hydrodynamic performance of a typical SEMI FPU. Through this study, it is found that:

I) Increasing hull draft can effectively suppress heave, surge and pitch motions. The airgap can be improved by increasing draft in irregular waves with $T_{p}$ less than 14 seconds. However, the airgap tends to decrease for $T_{p}$ more than 14 seconds as draft increases.

II) Increasing column width $(\mathrm{CW})$ can reduce the pitch motion, but lead the wave elevation to increase around the column. Therefore, the airgap reduces significantly as CW increases.

III) Increasing column spacing (CS) causes larger heave and pitch motions so that the airgap is improved.

IV) Column corner radius (CCR) affects the heave resonant period. Increasing CCR results in longer heave cancellation and resonant periods so that the heave motion in irregular waves increases. Furthermore, the airgap is improved as CCR increases.

V) Increasing pontoon height $(\mathrm{PH})$ can lead heave resonant period to increase. Hence, the heave motion in extreme wave condition turns to get worse. However, the airgap decreases because the wave elevation increases and it's more dominant than the growth of heave. Therefore, smaller pontoon height can cause lower heave motion and higher airgap simultaneously.

VI) Reducing pontoon width (PW) can reduce both the heave and pitch motions. Airgap is improved as PW increases in extreme wave condition.

VII) The size of cakepiece (CP) can affect the heave motion. Larger $\mathrm{CP}$ will cause heave motion to increase and airgap can be improved.

\section{Acknowledgements}

The first author (X. Z.) gratefully acknowledges the financial support from Chinese government through the 1000-Young Talent Program with Grant No. 15Z127060020, and National Natural Science Foundation of China with Grant No. 51679138. The financial support from National Basic Research of China with Grant No. 2015CB251203 and No. 2013CB036103 is also gratefully acknowledged. Partial financial support is provided by the Chun Tsung Program through Shanghai Jiao Tong University.

\section{Reference}

Akagi, S., Ito, K., 1984. Optimal design of semisubmersible form by minimizing its motion in random seas. J. Mechanisms, Transmissions, and Automation in Design 106, 23-30. 
Akagi, S., Yokoyama, R., Ito, K., 1984. Optimal design of semisubmersible's form based on systems analysis. J. Mechanisms, Transmissions, and Automation in Design 106, 524-530.

API RP 2MET, 2014. Derivation of metocean design and operating conditions. In: First Edition.

API RP 2SK, 2005. Recommended practice for design and analysis of stationkeeping systems for floating structures, October, 2005. In: Third Edition.

Birk, L., 2007. Application of constraint multi-objective optimization to the design of offshorestructure hulls. In: Proceedings of the 26th International Conference on Offshore Mechanics and Arctic Engineering, OMAE200729625, San Diego, California, USA.

Birk, L., Clauss, G. F., 2008. Optimization of offshore structures based on linear analysis of wave-body interaction. In: Proceedings of the 27th International Conference on Offshore Mechanics and Arctic Engineering, OMAE2008-57631, Estoril, Portugal.

Cermelli, C., Roddier, D., Busso, C., 2004. Minifloat: a novel concept of minimal floating platform for marginal field development. In: Proceedings of the fourteenth International offshore and polar engineering conference, Toulon, France.

Clauss, G. F., Birk, L., 1994. Optimization the motion behavior of offshore structures. In: Proceedings of BOSS' 94 Conferenece, Cambridge, MA, USA.

DNV-RP-C205, 2007. Recommended Practice- Environmental Conditions and Environmental Loads.

Lee, C. H., 1999. WAMIT theory manual. Department of Ocean Engineering, MIT, MA.

Lee, J. Y., Clauss, G. F., 2007a. Automated development of floating offshorestructures in deepwater with verified global performances by coupled analysis. In: Proceedings of the Seventeenth International Offshore and Polar Engineering Conference, Lisbon, Portugal.

Lee, J. Y., Clauss, G. F., 2007b. Effect of lateral keel and blisters on semisubmersible for the minimization of heave motion. In: Proceedings of the Seventeenth International Offshore and Polar Engineering Conference, Lisbon, Portugal, July, 2007.

Lee, J. Y., Koo, B., Clauss, G. F., 2007. Automated design of a tension leg platform with minimized tendon fatigue damage and its verification by a fully coupled analysis. Ship Technol. Res. 54 (1), 11-27.

Lee, J. Y., Lim, S. J., 2008. Hull form optimization of a tension-leg platform based on coupled analysis. In: Proceedings of the Eighteenth International Offshore and Polar Engineering Conference, Vancouver, Canada.

Liapis, S., Li, Y., Lu, H., Peng, T., 2015. Bigfoot dva semi-submersible model tests and comparison with numerical predictions. In: Proceedings of the 34th International Conference on Ocean, Offshore and Arctic Engineering, OMAE 2015-42411, St. John's, Newfoundland, Canada. 
Lu, J. Y., Hansen, V. L., Viteri, H. M., Lee, M., Huyse, L., 2013. Deepwater dry tree semi technology readinessperspectives of operator and classification society. In: Proceedings of Offshore Technology Conference, Houston, USA.

Mansour, A., Kumar, D., 2013. High performance semisubmersible design for dry tree applications in harsh environment. In: Proceedings of the 32nd International Conference on Ocean, Offshore and Arctic Engineering, OMAE 2013-10922, Nantes, France.

Newman, J. N., 1974. Second order, slowly varying forces on vessels in irregular waves. In: Int. Symp. Dynamics of Marine Vehicles and Struct. in Waves.

Newman, J. N., 1977. Marine Hydrodynamics. MIT Press.

Nishimoto, K., Leite, A. J. P., 1993. Effect of lateral keel and blisters on semisubmersible for the minimization of heave motion. In: Proceedings of the Third International Offshore and Polar Engineering Conference, Sinpore, June, 1993.

Park, Y., Jang, B.-S., Kim, J. D., 2015. Hull-form optimization of semi-submersible fpu considering seakeeping capability and structural weight. Ship Technol. Res. 104, 714-724.

Roddier, D., Cermelli, C., Aubault, A., Weinstein, A., 2010. Windfloat: a floating foundation for offshore wind turbines. Journal of Renewable and Sustainable Energy 5, 033104.

Venzon, R. Z., Tancredi, T. P., deAndrade, B. L. R., 2013. Hull optimization of semi- submersible with seakeeping criteria evaluated with neural network response surface. In: Proceedings of 12th International Symposiumon Practical Design of Ships and Other Floating Structures. PRADS2013, Changwon, Korea, pp.944-952.

WADAM, 2005. Wave Analysis by Diffraction and Morison Theory. In: SESAM User Manual.

Xia, J., Das, P. K., Karunakaran, D., 2008. A parametric design study for a semi/SCR system in northern north sea. Ocean Eng. 35, 1686-1699.

Xu, Q., 2011. A new semisubmersible design for improved heave motion, vortex induced motion and quayside stability. In: 30th International Conference on Ocean, Offshore and Arctic Engineering, OMAE 2011-49118, Rotterndam, The Netherlands.

Xu, Q., Kim, J., Bhaumik, T., OSullivan, J., Ermon, J., 2012. Validation of hvs semisubmersible VIM performance by model test and cfd. In: 31st International Conference on Ocean, Offshore and Arctic Engineering, OMAE 2012-49118, Rio de Janeiro, Brazil. 